\title{
CONFLICTOS Y DESARROLLOS DEL IMAGINARIO COLECTIVO: EL PAISAJE DE LA ALBUFERA Y EL SALER
}

\author{
Ester Alba Pagán \\ Aneta Vasileva Ivanova \\ Departament d'Història de l'Art. Universitat de València \\ ealba@uv.es, aneta.vasileva@uv.es
}

\section{RESUMEN}

La Dehesa del Saler forma parte de la Albufera, el espacio más problemático y al mismo tiempo, el más emblemático del patrimonio paisajístico valenciano. Su análisis no podría estar separado de una construcción histórica polifónica, tejida por un lado por los múltiples discursos que forman la historia del espacio real, humano y paisajístico y, a la vez, por aquellas voces que configuran un imaginario cultural con fuertes valores identitarios.

Palabras claves: Paisaje, Albufera, Saler, imaginario cultural, patrimonio.

\section{ABSTRACT}

The Dehesa of the Saler forms a part of the Albufera lagoon, the most problematic, and in the same time, the most emblematic space of the Valencian landscape heritage. Its analysis might not be separated from a historical polyphonic construction, woven by the multiple speeches that form the history of the real, human and landscape space and, simultaneously, by those voices that configure the cultural imaginary with strong identity values.

Keyworks: Landscape, Albufera, Saler, heritage, cultural imaginary.

Fecha de recepción: febrero 2016.

Fecha de aceptación: diciembre 2016. 


\section{INTRODUCCIÓN}

El mero acercamiento a la descripción de la Albufera se convierte en pregunta histórica. Un territorio hoy protegido, antropizado desde hace milenios, encerrado entre el Mediterráneo y el área suburbana de Valencia. Hogar de centenares de especies, cuya biodiversidad apenas recuerda ya aquella del pasado y cuyos componentes presentan cotas de cambio significativas. Su restinga litoral, la Dehesa, fue arrasada y reconstruida, su marjal fue convertido en arrozales, su lago pasó de las 30.000 has, en la antigüedad, a las 2.896 actuales (Momblanch, 2011; Roselló, 1995; Sanz, 1991). Mientras disminuía la superficie geográfica, aumentaba proporcionalmente la del mito: suma de la historia y la invención apasionada; los tintes vertidos en planos, cuadros, ilustraciones y textos se acumulan en una pátina que se espesa al diluirse en una cantidad de agua cada vez menor. Hoy en día nadie puede negar que la Albufera es entendida como un icono en el imaginario colectivo valenciano y que, como otros paisajes (Mata Olmo: 2004; 2010), se ha ido convirtiendo en un artefacto cultural de nuestra memoria.

Cuando Halbawchs $(1994 ; 2004)$ habla de la dimensión plural de la memoria, lo hace en alusión al término de memoria colectiva, en cuanto que hace referencia a la capacidad memorística, que trasciende los límites del individuo y, por tanto, tiene como sujeto a un colectivo. Los recuerdos son siempre individuales, lo que nos lleva a admitir la individualidad de la memoria basada en recuerdos. Pero la memoria es también un acto colectivo, condicionado por marcos sociales que funcionan como puntos de referencia; por ello, los recuerdos hallan su significado cuando son puestos en relación con las estructuras conceptuales creadas por los miembros de una comunidad: cultura, arte, medios de comunicación o literatura. Por ello, para Sánchez Zapatero (2010: 25-30) el concepto de memoria colectiva hace alusión a la capacidad de las sociedades para recordar, tanto como a la capacidad que adquieren en la construcción de la memoria individual. Quien recuerda es el sujeto, pero bajo los parámetros de la sociedad en la que se inserta. Es decir, la configuración mental del mundo es siempre social: puede hacer referencia a lugares y momentos concretos, pero es la capacidad simbólica la que alude a la memoria colectiva, como el conjunto de tradiciones, mitos, creencias, imágenes que poseen los miembros pertenecientes a un determinado grupo social. A ello se une la capacidad del territorio como articulador de la memoria, en el sentido defendido por Walter Benjamin en su Libro de los pasajes (2005), por el que los espacios se articulan como lugares en los que se tienen experiencias. Un mismo lugar aglutina lo que ha sido y el ahora, lo antiguo y el progreso, la mirada íntima y la colectiva. Benjamin recoge lo habitual de las travesías cotidianas de los habitantes de una ciudad y por ende del territorio, cuya comprensión se escribe en el espacio: un nuevo umbral para la percepción y la constitución de la memoria colectiva. Así, el territorio y la presencia del hombre en él, representan no sólo el análisis de su transformación, urbanización, protección, sino sobre todo de su propia existencia. Los espacios de configuración de la memoria colectiva adquieren una capacidad narrativa, en el sentido de que posibilita la transmisión de una experiencia, la reflexión social o la búsqueda de la conciencia social. Como Anna Maria Guash (2014: 81-91) expresa, los procesos de globalización conllevan la posibilidad de ampliar nuestros horizontes, para conectarnos con otras sociedades, con otras culturas, gentes o pensamientos en lo que Appadurai (2004) ha llamado experiencias diálogicas. En los últimos años se observa una ten- 
dencia a la valoración asociada al llamado fenómeno del Memory Effect, que plantea una cierta obsesión por la memoria en sus diferentes facetas: almacenada, instintiva, colectiva, individual o cultural (Colmeiro, 2005; Walter, 2005; Green, 2008: 681-697; Ramos, 1989: 63-81; Shotter, 1990: 137-156). Por ello, la mirada global no debe ser vista como un proceso externo, abstracto, sino como un proceso local, como reflexión sobre la memoria y lo que somos, una alteridad identitaria de la conflictiva vida cotidiana en el sentido social e individual. La obsesión por la memoria "histórica", desde el análisis no histórico sino antropológico y geográfico, halla su respuesta en los cambios acelerados experimentados en un corto espacio de tiempo, traducidos en la configuración de lo que Zygmunt Bauman (2000) ha denominado la modernidad líquida. Esta modernidad, caracterizada por la volatilidad, fragilidad, inseguridad e incertidumbre de realidades y conceptos, necesita anclarse al pasado y reflexionar sobre el significado histórico de los cambios sociales y sobre las distintas realidades percibidas sobre un mismo territorio.

Frente a los cambios tecnológicos, a la rapidez de las mutaciones sociales, a la transformación natural y urbana, territorial, la sociedad analiza y evoca la memoria desde la perspectiva del individuo y desde la preocupación social como medio de enfrentar, a modo de catarsis colectiva, los problemas de la sociedad presente. Evocar la historia de La Albufera de Valencia y el Saler obliga a reconocer que no tienen una historia global sino una red de historias, que oscilan entre lo físico, lo antropológico y lo jurídico, que cambian en función de la voz narradora. Como establece Jürgen Habermas, en su Modernity versus Postmodernity (New German Critique, 1981), la experiencia estética y contemplativa no sólo es capaz de renovar las interpretaciones de nuestra necesidad de ver y apreciar cómo percibimos el mundo, sino que también es capaz de intervenir en la articulación cognitiva del propio proceso de contemplación. Alcanzar la comprensión de un fenómeno cultural determinado, viene configurado, en parte, por condicionamientos espaciales, temporales y culturales; por conocimientos previos o prejuicios culturales que conforman nuestra memoria cultural. Ello permite apreciar de qué manera se han mantenido, destruido o mutado los valores culturales, en base a criterios sociales, políticos y económicos, asociados al bien cultural. Esta consideración entiende el patrimonio como algo vinculado no tanto al sentimiento de identidad, sino que se acerca más a la noción de memoria conservada o perdida. De alguna manera, el análisis de estos significados nos permite trazar las líneas que han marcado, en el devenir histórico, las decisiones que han pesado sobre la conservación, sobre la modificación o reconstrucción de sus usos y funciones, sobre la destrucción o sobre las valoraciones simbólicas del patrimonio en el tiempo.

\section{LA HISTORIA}

Desde Jaime I, la Albufera y la Dehesa son propiedad real. Enumerar los nombres de los monarcas que han engrosado la documentación jurídica equivaldría a un repaso de toda la historia medieval y moderna: casi no hay soberano que no haya confirmado su derecho sobre los beneficios del lago y del bosque. Con el avance de los siglos la ordenación del Patrimonio Real se hizo más compleja y restrictiva, las normas reinciden en los derechos soberanos sobre una quinta parte del pescado obtenido, vuelven a prohibir la tala, caza y labranza furtivas, desarrollan una serie de medidas punitivas y de vigilancia. El número 
de páginas de los archivos es significativo: nadie legislaría con tanto afán unos derechos que hayan sido respetados (Momblanch, 2011: 64-135; Rosselló, 1995: 102-107). Para entender el uso que dieron a los humedales y a la restinga sus reales propietarios, después de haber otorgado a sus súbditos el privilegio de pescar y también de cazar, esto último con fuertes limitaciones temporales, disponemos de otra serie de documentos. Son descripciones elegíacas de los cronistas y poetas, dedicadas a las proezas cinegéticas de los monarcas. Una vez más, disponemos de una larga lista de nobles cazadores: sería más fácil resumirla afirmando que no hay detentador de la propiedad del lago que no haya traído aquí su corte para convertir la caza en un gigantesco espectáculo. Las cacerías reales conmemoraban momentos históricos importantes, como bodas o presentaciones del monarca a los ciudadanos valencianos. Fueron escenarios solemnes, remodelados por una escenografía festiva, batallas fingidas de tropas disfrazadas, damas engalanadas, barcas tapizadas de oro y damasco, música estridente, tópicos que llegaron al paroxismo durante el gobierno de los Austrias.

... y van los marinos azotando las aguas con aquellos remos con tanto estruendo de música y bossería de contento que no se tuvo por seguro el gran Neptuno de ver la sobredicha y gran flota de barcos y armada real a quien la armada de las Indias les hes tributaria (De Gauna, Relación de las fiestas celebradas en Valencia con motivo del casamiento de Felipe III, en Momblanch, 2011: 101).

Entre tantas sublimes figuras que durante semanas cazaban aves en el lago y jabalíes en la Dehesa con pompa y gloria, algunos han dejado en la memoria popular anécdotas de dudosa dignidad, como las proezas culinarias del Borbón, Carlos IV, tan adicto al empacho con anguilas que "fue preciso quitárselas de delante [mintiéndole] que ya no había más anguilas" (Diario de Valencia, 26-XI-1805, Momblanch, 2011:126). Mientras tanto, la coreografía lacustre había cambiado, adaptándose al gusto decimonónico: cazadores y cazadoras se afanaban en mostrar a la multitud más bien gracia arcádica y elegancia florida, junto con sus vestidos a la última moda que la prensa comentaría en detalles.

En la jurisdicción directa de la Albufera existe otra línea, que resultaría más transcendente que la dedicada a asegurar a la monarquía su ostentación cinegética y a sus súbditos, el privilegio de los restos. A lo largo de su historia el patrimonio real conoció periodos puntuales de cesión de los beneficios a favor de nobles cercanos a la corona (Arciniega, 2015). Estos episodios, especialmente relevantes a partir de la llegada de los Borbones, se convertirían en uno de los factores para el cambio radical del ecosistema de la zona (Rosselló, 1995: 1037). El periodo coincidió con el auge del cultivo del arroz, práctica que se había considerado indeseable por su alta insalubridad y había sido prohibido reiteradamente desde el siglo XV. En 1753 una real orden legalizó las acciones furtivas de conversión del marjal en campos de arroz, abriendo camino a la intensificación del cambio de la fisonomía de la Albufera (Albiñana y Hernández, 1983: 66-8). Pero la colonización agraria, con el beneplácito de la ley, no se expresó solo en aterramientos. También consistió en un incremento de las entradas de las aguas, pasando de una gola a las actuales tres y otra serie de medidas hidráulicas que, a largo plazo, reforzaron los procesos naturales de dulcificación de las aguas del lago (Sanchis Ibor, 1998: 135-7). De hecho, una de las claves de la historia oficial de la Albufera y del Saler, fue 
el constante interés hacia estos espacios como objetos de grandes proyectos transformadores, relacionados, más que con la economía agraria, con aquella orientada a las comunicaciones comerciales.

Anteriormente, las actuaciones más significativas sobre caminos y su embellecimiento asociado al recreo se habían centrado en el lugar de esparcimiento que constituía la Albufera. Una de las primeras acciones es datada por Luis Arciniega (2015) en 1580, cuando Antonio Calatayud y Toledo y Mariana Çanoguera, señores de Catarroja, costearon los gastos del camino carretero para carros y coches, que había de unir el camino real desde Catarroja hasta la Albufera, donde la gente podía acudir como lugar de recreo. Más tarde, este camino se puso al servicio de los desplazamientos de Felipe II y Felipe III, destacando las dobles bodas celebradas en Valencia en 1599 y en las que el esparcimiento bucólico asociado a la Albufera formó parte de las celebraciones. Nada más lejos del espíritu del siglo siguiente. Contemplando los megaproyectos ilustrados no podemos sino reconocer que el lago atrajo, mucho antes que su territorio vecino de l'Horta, el interés de planteamientos urbanizadores, en el amplio sentido del término. El primer gran proyecto ingenieril se debe a Pedro Caro, marqués de la Romana y fue formulado en 1764, pero guarda filiación con ideas utópicas de siglos anteriores, obsesionados con la apertura de canales para potenciar la comunicación comercial, haciendo navegables los ríos hacia Castilla o reorientando la ciudad hacia el comercio marítimo (Albiñana yHernández, 1983: 58-9; Momblanch, 2011: 159 y post.; Roselló, 1995: 120). El marqués de la Romana propuso desechar la idea de un problemático puerto en el Grao de Valencia en favor de la construcción de uno en Cullera, conectado con la ciudad por medio de un canal que cruzase la Albufera y el terreno entre el Turia y el Júcar, favoreciendo, de paso, tanto la exportación de pescado como el regadío para la expansión agraria arrocera. La Real Sociedad Económica de Amigos del País respaldó el proyecto con entusiasmo.

Estas iniciativas ilustradas parten de la mirada de los primeros cronistas, que ofrecen una visión minuciosa y precisa del observador, más allá de las apreciaciones bucólicas y ensoñadoras. Es el caso de las Observaciones sobre la Historia Natural, Geografía, Agricultura, población y frutos del reyno de Valencia, del botánico Antonio José Cavanilles (1795-1797). Este nuevo género literario surge bajo el auspicio del pensamiento ilustrado. Estos viajeros científicos transformaron sus dietarios de viaje y observaciones de campo en libros que se caracterizarían por una ordenada sistematización de sus anotaciones. Los recorridos de Cavanilles por el reyno de Valencia obedecían a la necesidad y al interés de la monarquía española por conocer el territorio y la sociedad donde se estaban aplicando las políticas del Despotismo Ilustrado (Mateu, 1997). Para el botánico el interés radica especialmente en "el cálculo de la población y de los frutos, por donde se viene en conocimiento así de la calidad del suelo, como de la industria de sus habitantes" (Cavanilles, 1795, p. I), y especialmente el estudio de la captación de las aguas y su conducción como elementos necesarios en el saneamiento higienista de las poblaciones. La idea inmanente en los textos de Cavanilles se centra en la obtención de aguas para el riego de las huertas y la transformación de las tierras pantanosas que, en la mirada del ilustrado, viciaban el aire y eran fuente de enfermedades y fiebres. Ideas que serán recogidas en 1846, por Pascual Madoz en su Diccionario Geográfico-Estadístico-Histórico de España y sus posesiones de ultramar. Las iniciativas hidráulicas ilustradas, inicialmente sin aplicación, presentan otros episodios, que varían desde numerosos proyectos de desagües hasta propuestas de desecación total del lago, como 
es el caso del ingeniero flamenco Pedro Torbé (Albiñana, Hernández, 1983: 69-71). Pero el auténtico receptor de la idea de la canalización comercial del lago fue el siglo del progreso, el XIX. El 8 de enero de 1854 la Sociedad del Canal de la Albufera inauguró las obras de un canal de navegación ya más modesto, entre Valencia y Sueca, obra ensalzada por Vicente Boix con estas estrofas:

Oiréis el rumor: ¡el siglo avanza! (...)

Veréis cruzar su solitaria esfera

Columnas de vapor: ¡con él la vida!

¡Risueño el provenir ya nos convida!

¡Fuente de bendición es la Albufera!

(Momblanch, 2011: 161)

Como tantos proyectos anteriores y posteriores, este tampoco tardó en caer en bancarrota.

La mayor singularidad del paisaje de la Albufera está relacionada con su antropización. Sin embargo, la historia de los auténticos habitantes del lago, de la gente que vivió en él y de él y contribuyó a una buena parte de sus drásticos cambios, ha sido contada con menor frecuencia que la oficial, y es bien diferente. La pesca se practicaba como mínimo desde la época musulmana, aunque el asentamiento definitivo de pescadores, procedentes de los pueblos de las orillas, en el más tardío núcleo de la isla de Palmar, se produjo en el XVIII. Pero la regularización de las comunidades de pescadores es tan antigua como la conquista y, durante los siglos del medioevo y de la edad moderna, su vida cambió sorprendentemente poco. Las comunidades de pescadores, antecesoras de las actuales comunidades de El Palmar, Catarroja y Silla, nunca fueron propietarias del medio del que vivían y los beneficios que este les proporcionaba eran bien escasos, además de la elevada furtividad, como testimonia el ya mencionado afán legislador. El precio del pescado del lago siempre fue muy inferior al de la pesca marítima y las variedades que los pescadores podían dedicar a su propia mesa eran las de peor calidad alimenticia. Joan Fuster, escritor de Sueca y acérrimo enemigo de los tópicos históricos, describe la dieta local, en nada parecida a las opíparas paellas que hoy relacionamos con la imagen cultural de la zona. Con escaso acceso a la caza y con las limitaciones mencionadas de la pesca, la dieta local se caracterizaba por hechos singulares: Fuster afirma que hasta bien entrado siglo XX gatos, serpientes y ratas del canal eran parte habitual del menú (1993). Es comprensible que, en tales condiciones, los pescadores desarrollaran un sistema de trabajo en el que las tareas y las responsabilidades, se repartían en inusual igualdad. Un acertado estudio etnográfico afirma que los únicos cambios que han conocido las comunidades desde tiempos de Jaime I podrían reducirse a los voluminosos aterramientos entre los siglos XIX y XX; ya en el XX, a la introducción de motores para las barcas y redes de nylon que transformaron por completo la organización del trabajo, y al desastre ecológico desencadenado por la urbanización e industrialización desarrollista, hoy paliado parcialmente, pero en un contexto de crisis de todas las actividades económicas tradicionales (Sanmartin, 2008: 247-252).

Los aterramientos, que a la larga limitaron el lago a menos de una cuarta parte de su superficie premoderna, fueron distribuidos en el tiempo de una manera muy desigual, pero siempre supusieron una tarea titánica. El barro del fondo de los canales se acarreaba en barcas con rudimentarias herramientas. Si para ganar de este modo una hectárea de superficie 
fueron necesarias entre 1500 y 2.000 embarcaciones, el esfuerzo resultante es equiparable al de las pirámides. Ya mencionamos que los factores que posibilitaron este proceso tienen su relación con la historia oficial, sobre todo en la época de los aterramientos más drásticos, entre las últimas décadas decimonónicas y las primeras del XX, cuando se convirtieron en campos casi 2.000 has (Sanz, 1991: 40-41), escenificando en la Albufera aquella epopeya de cambios sociales que inmortalizó Blasco Ibáñez en Cañas y Barro. Si la colonización agraria del lago empezó con el nuevo orden económico del XVIII, la lucha contra la propiedad real de la zona se convirtió en símbolo de la burguesía más radical y en un movimiento violento. Cuando hacia 1838 María Cristina de Borbón intentó lo imposible para reclamar sus beneficios del lago, sus propios funcionarios le advirtieron de la urgencia de ceder a las presiones para flexibilizar el sistema de pago, puesto que si no:

podría su Majestad despedirse de cobrar jamás ni un grano de arroz, a no ser que se hubiese presentado fuerza considerablemente armada y aún entonces peligraba se hubieran revolucionado los pueblos. (cit. en García Monerris, 1983: 125).

Con semejantes condiciones, en 1865, Isabel II optó por el reconciliador gesto de renunciar al patrimonio real del lago y de la franja litoral, pasando este al patrimonio estatal. Cuarenta y seis años más tarde, el 23 de junio de 1911, cuando la zona se convirtió oficialmente en propiedad y responsabilidad del Ayuntamiento de Valencia (Rosselló, 1995: 108), el paisaje había sufrido el cambio más extremo de toda su historia. Por supuesto, los que promovieron los cambios administrativos, y algo más, fueron los representantes de la gran burguesía valenciana, que aprovecharon la expansión agraria para consolidarse como fuerza económica. Pero aquellos que cargaron las innumerables barquitas de fango con poco más que sus manos fueron otros. En primer lugar, fueron los habitantes de los pueblos cercanos quienes se lanzaron a hacer aterramientos, poco más tarde, obligados por esta competencia, lo hicieron las propias comunidades de pescadores, transformando así no solo su medio natural sino también su propio ancestral modo de vida y de miseria. En la época de los aterramientos permitidos y estimulados, la justificación del pescador, en vía de convertirse en campesino, no era demasiado distinta de la que lo movía en tiempos en que había que escatimar la quinta del pescado del rey y completar la supervivencia con caza, tala y otros usos furtivos de la restinga, hasta que la Dehesa necesitó ser repoblada y vigilada de forma permanente. La motivación dominante de la acción del habitante de la Albufera fue resumida lapidariamente por Fuster: "Fam és la paraula clau” (1993: 103).

La historia contemporánea de la Albufera y del Saler es incomprensible sin el análisis de la relación que establecieron entre sí sus dos vecinos; el histórico: l'Horta, y el actual: la ciudad de Valencia. La metrópolis, que debe su consolidación y desarrollo a sus vínculos con el campo que la rodea, se convirtió, desde los primeros ensanches más allá de sus derribadas murallas, en el invasor de su territorio originario, en un proceso que hoy amenaza por terminar con la destrucción definitiva de l'Horta (Romero, Francés, 2012). Uno de los factores importantes que caracterizaron aquel imparable crecimiento fue la ausencia real de planteamientos urbanizadores globales (Boira, 2004; Sorribes, 1985). Valencia, ciudad de medianos capitales financieros y de pensamiento urbanístico difuso, crecía de manera radio-concéntrica, a lo largo de las carreteras, donde se construía fragmentando y circundando el campo suburbano. El modelo de expan- 
sión tentacular se basaba en la inicial diferencia de precios entre el suelo productivo de l'Horta y el suelo urbano: hasta bien entrado el siglo XX el primero fue muy superior y el balance de los precios cambiaba solo en las parcelas situadas a lo largo de las nuevas infraestructuras viarias, lo que desencadenaba la especulación y, a medida que los procesos avanzaban, marginaba las zonas rurales, degradando la tradicional red hidráulica. Este proceso se realimentó con el permanente descenso de los beneficios de la agricultura tradicional en las últimas décadas del siglo XX (Romero, Miquel 2012; Cabrejas, García, 1997). No es de extrañar, entonces, que los desencadenantes de la destrucción más grave, los “golpes de gracia” dados a l'Horta valenciana, procedieran de los grandes proyectos vinculados a las infraestructuras de comunicación y comercio, como el Plan Sur de 1958, que remodeló el curso de los últimos tramos del río Turia, y el proyecto de ampliación del puerto, que culminó la devastación organizada en 1998. Paradójicamente, los artífices del megaproyecto desarrollista se armaron de la conciencia de la necesidad de una planificación global para salvar los restos del equilibrio roto entre ciudad y campo, premisa que siempre quedó sobre el papel, entre consignas totalitarias, rápidamente canjeadas por las ventajas especulativas. Desde estas bases anunciaban el Plan Sur como la barrera definitiva contra posteriores expansiones sobre l’Horta, más allá del nuevo lecho, sin mencionar que el plan suponía la destrucción asegurada del resto de campo que quedaba entre la ciudad y el nuevo cauce del río (Boira, 2004: 106). Para la Albufera y el Saler, el sueño de los ilustrados se había convertido en una pesadilla real y palpable. Al inicio de los años sesenta ambas lindaban con la nueva "muralla" que tenía que limitar la nueva Gran Valencia. Faltaba un soplo de viento para que esta última muralla cayese, reiniciando todo el proceso de expansión tentacular, al proyectar carreteras en cuyos bordes crecerían rápidamente viviendas y naves industriales.

En estas fechas se realizó, parcialmente, el megaproyecto que provocó reacciones que cambiaron no solo la historia de la Albufera, sino también la de toda la sociedad valenciana. La gigantesca operación especulativa que, entre 1964 y 1978, convirtió a la Dehesa en presa de una urbanización destinada al turismo de lujo, provocó una reacción que desembocó en el inicio de los movimientos ecologistas y civiles (Mateu y Domínguez, 2011). Una inusitada movilización ciudadana, inscrita en el fracaso económico de la operación especulativa, que consiguió la paralización de las obras y, a largo plazo, su posterior reversión parcial y la creación del Parque Natural de Albufera. Lo que después fue reivindicado con las mismas desesperadas acciones ciudadanas para lo que quedaba de l'Horta, se hizo realidad solo para la Albufera y la Dehesa. De modo parcial, sin embargo. La contaminación y otros usos derivados de la fuerte industrialización y el desarrollo urbanístico de los pueblos periféricos, unidos al persistente desequilibrio social de una zona, donde todas las actividades tradicionales están en retroceso, contribuyen a que el parque nunca esté verdaderamente a salvo (Cabrejas, García, 1997). Pero este conflicto ya forma parte de otro tema: el referente al imaginario sobre la Albufera, que había pasado a simbolizar ideas diferentes.

\section{EL IMAGINARIO}

En los albores de la modernidad parecía que la imagen de la Albufera rebosase de contradicciones. Mientras algunos viajeros la entrelazaban con la visión de l'Horta, esa Arcadia donde convivían armónicamente hombre y naturaleza, otros no osaban acercarse demasiado 
a las marismas, denunciadas por los ilustrados como foco de paludismo. Nada sorprendente; el poder oficial promovía apologías de la caza, creaciones gráficas (fig.1) y poéticas, donde la excesiva abundancia, en medio de unas fuerzas naturales incomprensibles, configuraba la absurda lógica del mundo al revés:

Las aves no cabían en el viento

ni en el agua los peses, y assí viste

entrar las aves en el agua bella

y los peces bailando salir della

(Gaspar Aguilar, en Momblanch, 2011: 102)

Figura 1

CAZA EN ALBUFERA. PLATO DE MANISES, S. XV, MADRID, INSTITUTO VALENCIA

DE DON JUAN. EN GONZÁLEZ MARTÍ, 1952.

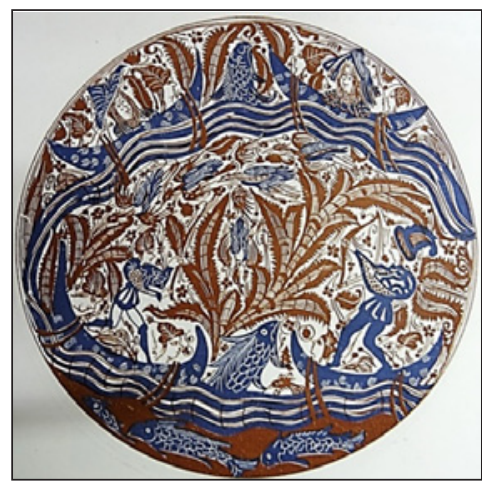

Figura 2

JOSEF YBAÑEZ, 1805, PLAN TOPOGRÁFICO DE LAALBUFERA, CARTOTECA DE UVEG. UNO DE LOS NUMEROSOS MAPAS, FUENTES CLAVE PARA EL ESTUDIO HISTÓRICO DE LA ZONA.

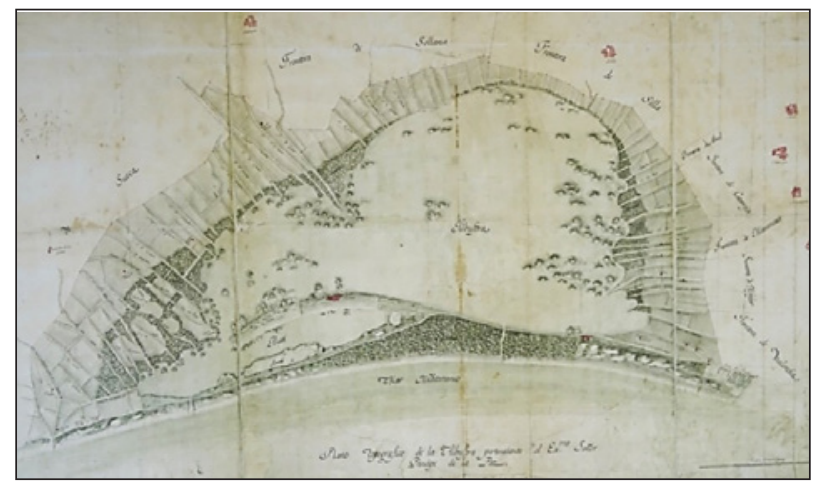

La confluencia de las imágenes de la Albufera y de su espacio vecino tiene su lógica geográfica. La ubicación del lago en el camino real a Valencia desde el sur hace que pronto 
sea destacada en las crónicas de los viajeros, personajes ilustres que pasaron por los caminos situados a orillas del lago: Fadrique Enríquez de Ribera, marqués de Tarifa, en diciembre de 1518, la atravesó en su ruta hacia Tierra Santa; Dom Edme Saulieu, In mei 1532, trekt de abt van Clairvaux, Dom Edme de Saulieu met zijn gevolg van Montesa (Valencia) naar Monsalud (Castilië).abad de Claraval, y su secretario Claude de Bronseval lo hicieron durante su visita en 1532 y 1533 a las casas cistercienses de la Península Ibérica; Jacob Cuelvis en 1599; el viajero M.M. en 1617; Des Essarts D’Angers, caballero natural de Angers, en 1659; Domenico Laffi en 1673 y 1687 (Arciniega, 2015), y más tarde Antonio Ponz (1774) y Richard Ford (1845). Uno de los elementos más reiteradamente elogiados era la naturaleza del camino, poniendo el acento en el efecto paisajístico del ambiente. La presencia del lago y de las tierras cultivadas a sus márgenes fue la característica territorial destacada de manera sostenida. En el Llibre dels Feits Blasco d'Alagó transmitía a Jaime I las siguientes inspiradoras y alentadoras palabras: "E no ha vui dejús Déu tan delitós llogar com és la ciutat de València e tot aquell regne, e ten bé set jornades de terra de llonc" (cit. en Soler, 1998: 217 244). Una realidad paisajística que se trasladó al pensamiento cristiano, especialmente a través de la obra del franciscano Francesc Eiximenis quien en el Regiment de la Cosa Pública (1383, publicado en 1499), dirigido a los jurados de Valencia, planteaba la dimensión poética del paisaje y defendía su cuidado y disfrute, al aconsejar plantar árboles en los marjales para embellecimiento de la huerta (Arciniega, 2015).

Desde ese momento, las alusiones a la dimensión estética de la fértil huerta valenciana han significado un tópico presente en los libros de viajes y en las descripciones de aquellos que nos visitaron (Sala, 1999). Estas ideas sobre la belleza del entorno de la ciudad, incluso comparándola con un jardín perfecto o con el Paraíso en la concepción de John Milton, fueron constantes en siglos posteriores, como lo atestiguan, por ejemplo, el inglés Willian Cecil, los franceses Barthélemy Joly, Des Essarts, el cardenal de Retz o los ingleses Joseph Townsend, Richard Twis, John Talbot Dillon y J. Marshall (Ribbans, 1955). Más tarde, en Les Delices de l'Espagne (1707), síntesis de opiniones del siglo anterior, se destacaba cómo el camino de Xàtiva a Valencia era uno de los más bellos y encantadores del mundo, que conducía a un jardín perpetuo con variedad de árboles frutales, una tierra extremadamente feraz donde la naturaleza parecía dar sus bienes a manos llenas, y con múltiples jardines de recreo. Por su parte, Christian August Fischer, que visitó tierras valencianas en 1797, alabó la virtud de lo que describió como el país celestial de la primavera (Arciniega, 2015). Sin embargo, mientras l'Horta fue admirada y generalmente ignorada como objeto de estudio o legislación reformadora, la Albufera fue estudiada y su transformación soñada con obsesión. Sus aves y peces eran contadas y clasificadas (Escolano, Orellana, Tomás de Villanueva, Cavanilles), sus orillas cartografiadas sin descanso (fig.2), sus medidas, discutidas apasionadamente. Como si aquella sobreabundancia de caos y contrastes ofendiera la razón ilustrada en tal grado, que tuviese que invocar incesantemente las divinidades de las matemáticas y del desarrollo estrictamente planificado para instaurar el orden.

En las últimas décadas del XIX, la imagen fantástica de la Albufera fue fusionada con el emblema de l'Horta definitivamente, asumiendo características del Levante Feliz como su "cielo diáfano y azul que ríe" (cit. en Sanchis Ibor, 2007: 247). El paralelismo maduró en los escritos del artífice del mito de la Renaixença sobre l'Horta y el primer verdadero poeta de Albufera: Teodoro Llorente. Su visón de l'Horta, destinada a convertirse en quintaesencia 
del sentimiento identitario valenciano, dibujaba un mundo de fraternidad y progreso utópicos, un espacio capaz de integrar las contradicciones de la naturaleza antropizada, el trabajo agrícola ennoblecido y la industria puesta al servicio de un ideal común (Boira, 2004: 97). En su Valencia (1887) podemos observar cómo la imagen marginal y enigmática de la Albufera acabó formando parte de la utopía de l'Horta. La poesía de la Albufera de Llorente es la del contraste y la variedad, entre "el sol de fuego, reverberando en el agua" y "el horizonte caliginoso", pero también entre la "palúdica e impenetrable vegetación" y "las airosas espigas de oro pálido" del arrozal, creación del "labrador infatigable" que ha convertido un paisaje incomprensible en un símbolo. Siguiendo este esquema, el poeta comparaba lo particular con lo universal, buscando referencias en destinos e imágenes románticas. Mientras en los depósitos de las "barracas, muy enjalbegadas y limpias [...] se enroscan las anguilas, como las serpientes del Laocoonte" (fig.3), el pintoresco símbolo consagraba el tipo costumbrista con cara humana y se mitificaba (Llorente, 1889: 494-498).

Nuestra percepción del mitologema gráfico de la Albufera y su Dehesa, creada en el XIX tardío, ha quedado oscurecida por la pérdida de la mayoría de las obras pictóricas (Llorente, 1889, vol. 2: 494-498). Las imágenes anteriores son mucho más escasas: apenas contamos con algunas notables excepciones, como la vista que formó parte de la selección de testimonios gráficos que el pintor Anton van der Wyngaerde dejó de las tierras valencianas en 1563, completada con detalles de la diversidad y las posibilidades recreativas y productivas del lago (fig.4). A una distancia abismal de esta pragmática fascinación, las obras decimonónicas supervivientes evidencian los procesos de construcción del tópico regionalista y costumbrista (López Albert, 2006: 142-7). Y a la par vierten luz sobre la idiosincrasia valenciana del siglo artístico.

Valencia se desenvolvió en un ambiente social y plástico bastante diferente al de Madrid o Cataluña. En concreto, la pintura valenciana se alejó de la pintura francesa, y se acercó a la pintura italiana. Los pintores valencianos del siglo XIX, disfrutaron de las pensiones concedidas por la diputación con el fin de ampliar su formación artística en Roma. Allí se impregnaron de la obra de los pintores italianos que practicaban la pintura de paisaje à plein air, los Macchiaoli. Otra de las cuestiones fundamentales que se puede observar en la pintura de paisaje valenciana es la evidente influencia de la Institución Libre de Enseñanza, a través de la elección de los lugares representados: lugares familiares, cercanos, espacios que conforman parte del entorno y por tanto, de la vida del artista. (Pérez Rojas, 1998). Algunos retratan las zonas más cercanas a su pueblo natal o bien los alrededores de los sitios donde pasaban la temporada estival. Tal es el caso de Antonio Fillol, uno de los artistas más sobresalientes de la escena pictórica valenciana finisecular, que convirtió la captación del paisaje de la Albufera en un icono de la vida de sus gentes y un modelo del naturalismo propio de la pintura social (Bonet, 1995: 69-78).

La pintura de paisaje naturalista o realista es introducida en España por el pintor belga, Carlos de Haes, profesor de paisaje de la Academia de Bellas Artes de San Fernando de Madrid. Haes fue el promotor del excursionismo con el fin de captar la representación realista de lugares, pero la figura que verdaderamente hace del excursionismo un auténtico método pictórico fue Aureliano Beruete (Arias, 2007: 177-185). En este fenómeno inciden varios elementos que convergen en el tiempo: el fenómeno industrial del ferrocarril, que acortaba las distancias y permitió aproximarse a la naturaleza y redescubrir la montaña y 
otros paisajes, cuya contemplación era promovida por las sociedades geográficas excursionistas; la industrialización de los pigmentos pictóricos en tubos de estaño (que ya no habían de ser confeccionados a golpe de mortero en el taller del artista), y la influencia de la pintura realizada à plein air que reflejase un instante concreto, la naturalidad del color de la realidad natural bajo el matiz fugaz de la luz cambiante. El pintor aporta su propia visión, una mirada personal y diferente de su entorno natural, dando paso a la contemplación reflexiva, introspectiva de la naturaleza. Esta representación de lugares geográficos concretos supone un cambio respecto a la pintura de paisaje anterior. El artista se aproxima al paisaje autóctono y, a través de éste, conecta con la realidad. Ese carácter subjetivo, de lo particular, de lo cercano y próximo, se evidencia en la pintura de paisaje de los pintores del fin de siglo.

Así, en las últimas tres décadas del XIX, el paisajismo valenciano trazaba su propia, y a veces contradictoria, trayectoria dentro de los cambios en que se sumergía la pintura en general. Las novedosas ideas de Carlos de Haes, irradiadas desde la Academia de Madrid, se enfrentaban a un mercado difícil. Los gustos de la joven burguesía se estaban formando, influenciados por una incipiente y contradictoria crítica (López Albert, 2008: 105-115). En este incierto ambiente, entre debates que reflejaban la lucha entre la concepción realista y la idealista, el color y el dibujo, el interés hacia el hecho científico y las reglas consagradas, el recurso de lo típico se impregnaba de nuevos matices. La búsqueda de veracidad y detalle en un ambiente concreto que, sin embargo, ya se había mostrado paradigmático, podía imponerse con unas condiciones significativas. Si, según el propio Carlos de Haes, la garantía del valor artístico de un paisaje realista era la fidelidad al sentimiento individual que había inspirado al artista, la crítica valenciana ensalzaba solo aquellos paisajes que subrayaban "la luz, la verdad y la poesía" (López Albert, 2006: 63-70). Interpretemos: la luz estaba a punto de convertirse en el emblema del colorido y feliz Levante habitado; la verdad era un concepto difuso, y la poseía se refería a una búsqueda identitaria común, en vías de construcción.

Los resultados se evidencian en la recepción crítica de las numerosas representaciones de la Albufera de la época. Encontramos repetidos elogios a los contrastes cromáticos, en un abanico que parte de los límpidos colores cristalinos propios del Levante y engloba el misterio de los estados lumínicos cambiantes: tormentas, atardeceres y brumas, idiosincráticos de las aguas estancadas de los arrozales. Se reiteró la mención del valor que encerraba la representación de la vida de los habitantes: una vida laboriosa, tranquila, pintoresca (López Albert, 2006: 144-6) Quizá la reseña más representativa que sintetiza los tópicos vendibles es aquella que se publicó en el Catálogo Oficial de la Exposición Nacional de Bellas Artes, de 1884, sobre el pintor Salvador Abril y Blasco:

Ahora ha pintado dos cuadros deliciosos: uno de ellos, como tantos otros del mismo autor, del hermoso lago de la Albufera: aguas cristalinas, cielo sereno y luminoso, cañaverales lozanos, agrupamiento pintoresco y típico de barcas y aparatos de pesca: todo ello forma un conjunto, en el cual la naturaleza reviste esta poesía que tan grata es a nuestro ánimo (cit. en López Albert, 2006: 147).

Son aquellos mejores ejemplos pictóricos del detalle típico, como la Barca en la Albufera de Sorolla, los que sorprenden con un repentino y rompedor encuadre fragmentado de clara inspiración fotográfica y dan vida al renovado tópico, inyectándole calidad vanguardista. En 
este sentido, ni siquiera el único cuadro conocido de Antonio Muñoz Degrain dedicado a un paisaje de la Dehesa, supone una ruptura con la línea que pone la sensibilidad personal por el detalle concreto al servicio del mito, aun incorporando novedades para seguir perteneciendo al tiempo eterno. Sobre todo si lo insertamos en la trayectoria general del pintor. Dentro del conjunto de su obra encontramos una significativa abundancia de lagunas, que no se han podido nutrir sino de los recuerdos concretos, pero que han tomado los nombres más exóticos: desde los de parajes bíblicos hasta el de la Laguna Estigia. Así, el imaginario nutrido por los pintores fluctuaba del experimento de sabor científico del objetivo fotográfico a la figura poética común, que equiparaba las marcas de identidad local con la emoción de la mitología exótica universal. Entre estos polos se acumulaban litografías coloreadas y los ejemplos propiamente fotográficos de los primeros años del invento. Desde fechas muy tempranas, el detalle costumbrista simbólico de la Albufera, la barraca, desfiló sobre centenares de cajitas de fósforos. Con el resurgimiento del género de la pintura de paisaje en España a partir de la segunda mitad del siglo XIX, los paisajes, las costumbres y los tipos propiamente valencianos como l'Horta, el Cabanyal, la Malvarrosa y la Albufera, junto a la Godella y Rocafort de Pinazo, son constantemente representados por pintores como Sorolla, Benlliure, Ricardo Verde y Fillol, entre los más destacados. La Albufera se convirtió en fuente de inspiración pictórica duradera, a la vez que Vicente Blasco Ibáñez la relacionó con los dramas humanos de dos de sus novelas más reconocidas: La Barraca y Cañas y Barro. Aunque fue Fillol el pintor por excelencia del lago valenciano, de sus gentes, de la vida cotidiana y de su trabajo esforzado (Bonet, 1989: 317-322).

Se había metido entre ceja y ceja ser propietario, tener sus campos de arroz, no vivir de la pesca como el tío Paloma, que era el barquero más viejo de la Albufera; y solo - pues su familia únicamente le ayudaba a temporadas, cansándose ante la grandeza del trabajo- iba rellenando de tierra, traída de muy lejos, la charca profunda cedida por una señora rica que no sabía qué hacer con ella (Blasco Ibáñez, Cañas y Barro, 1902)

La fuerte presencia de las enseñanzas de la Institución Libre de Enseñanza en Valencia fue uno de los motivos por los que la pintura de paisaje experimentó un importante desarrollo entre los pintores valencianos (Hernández Perelló, 2015). Aunque la pintura de paisaje valenciana presenta un carácter propio, es innegable la influencia que ejerció en ella el ideario institucionista de Francisco Giner de los Ríos. El grupo insitucionista, en general, y el valenciano, en particular, surgió de las explicaciones que sobre la teoría krausista impartían Nicolás Salmerón y Francisco Giner en la Universidad. El núcleo institucionista valenciano estuvo conformado por intelectuales de orígenes diferentes: José Villó y Ruiz (1839-1907), Eduardo Pérez Pujol (1830-1894) de Salamanca, Alfredo Calderón y Arana (1850-1907) de Madrid, Aniceto Sela y Sampil (1863-1934) de Asturias, y un único valenciano, Eduardo Soler y Pérez (1845-1907). Su compromiso con la regeneración social valenciana a través de la educación, se plasmó en el Congreso Pedagógico de 1886 que versaba sobre la cuestión de la enseñanza en el país. Algunos institucionistas expresaban sus ideas a través de la prensa como El Mercantil Valenciano, y tenían una importante presencia en otras instituciones valencianas como en la Sociedad de Agricultura, en la Sociedad Económica de Amigos del 
País, en el Ateneo Mercantil, Científico-Literario y Obrero, en la Caja de Ahorros, y en la Cámara de Comercio. El amor por la naturaleza fue una característica común en todos los institucionistas; la Naturaleza había sido divinizada por los krausistas en su mística religiosa, por lo que tenía que ser ennoblecida. En este contexto regeneracionista, los componentes del grupo valenciano, especialmente Soler, Sela y Calderón, hicieron derivar este principio natural hacia una concepción educativa fuera del aula, en contacto con la naturaleza. Esta nueva visión de la naturaleza se tradujo en la realización de estudios geográficos, en el interés por el excursionismo, convencidos del valor educativo del contacto con la naturaleza y el paisaje, y en el auge de la literatura de viajes y en el desarrollo de la pintura de paisaje (Hernández, 2015). El primer tercio del siglo XX viene protagonizado, incluso en mayor grado, por el papel de la Institución Libre de Enseñanza, en la manera de mirar y aprender del paisaje y de la naturaleza. Pero, también, supone un camino de ida y vuelta, pues la contemplación personal e interiorizada del paisaje se aúna a la mirada científica, didáctica, como herramienta de aprendizaje. Frente al romanticismo y al bucolismo regionalista de las décadas anteriores, la mirada del pintor de paisaje inaugura el fin de la visión utópica de la naturaleza. Uno de los pintores más sobresalientes será Antonio Fillol, quien a través de su poética pictórica se configura como el introductor de la representación naturalista de los conflictos del territorio.

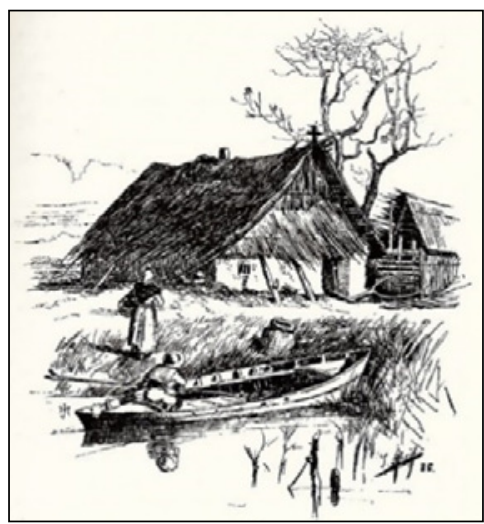

Figura 4

ANTON VAN DER WYNGAERDE, 1563, VISTA DE L'ALBUFERA DE VALĖNCIA.

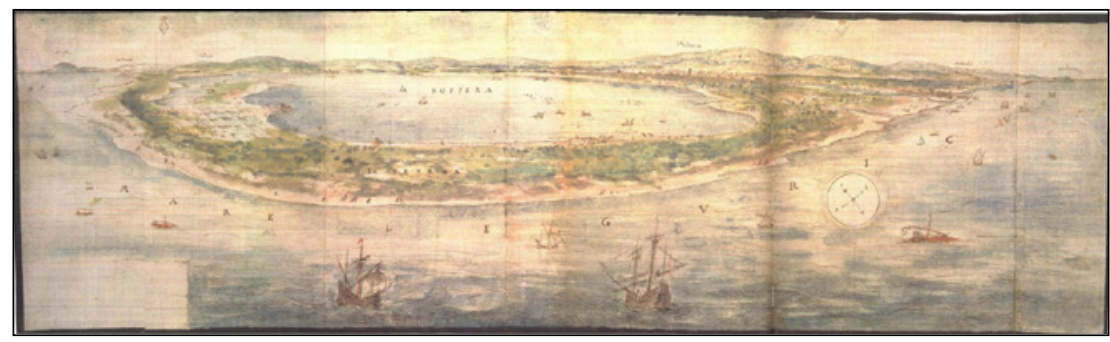




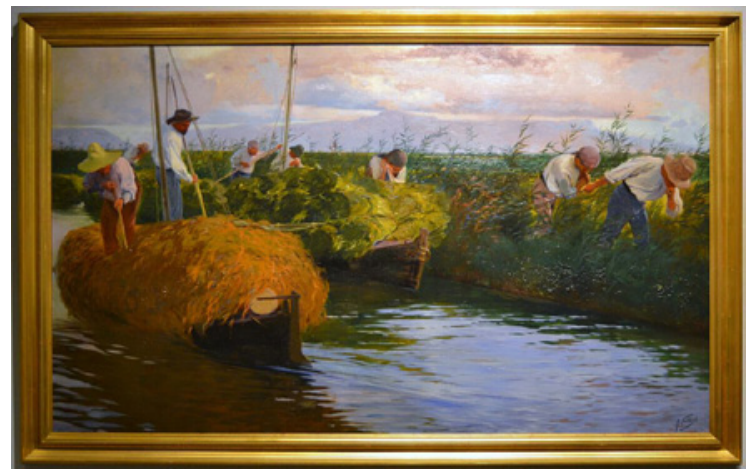

Su innovación destaca aún más, comparada con algunos pintores como Constantino Gómez, que en su imagen sobre la Albufera valenciana, conservada en el Ayuntamiento de Valencia, nos plantea una imagen compuesta a base de pinceladas expresivas, de cierto manchismo simbólico, en el que prima el efecto lumínico del atardecer sobre el cielo y el agua. Su visión interesada por los efectos lumínicos tiene más de Turner o de los pleineristas italianos que no del luminismo instantaneista y regionalista de Sorolla. Del conjunto pictórico sobresalen las barcas de pesca paralizadas en medio de un espejo inmóvil que confiere a la imagen una cierta atemporalidad. Pero más allá de la mirada puesta en las costumbres y en la narrativa exaltada de la vida cotidiana de los pescadores y arroceros del lago, su encuadre se centra en los juegos lumínicos y en la observación de los fenómenos atmosféricos. La mirada desnuda sobre el paisaje llega de la mano de José Benlliure. En su Arrozal en Sueca, los colores construyen el paisaje del arrozal segado que rompe con la frialdad invernal del cielo gris y plomizo. Benlliure se aleja de la representación de un paisaje al servicio del trabajo diario. Este ha concluido y las personas han abandonado los cultivos ordenando, con cierto carácter sistemático, la naturaleza antropizada. El color se atenúa con pinceladas suaves y nada empastadas, que acrecientan la percepción de una naturaleza continua hacia el horizonte. Similar visión es la que nos ofrece Antonio Fillol en La Sequiota (1903), una imagen del paisaje de la laguna de la Albufera desnuda, quieta, en la que el silencio resuena con ecos atemporales. El atardecer preña de malvas, lilas y rosáceos el cielo y los efectos lumínicos reverberan en la mansedumbre acuática. Solo las cañas y la red de pesca tendida entre las verticales rompen el primitivismo de un paisaje en el que la huella del hombre hace su presencia. La mirada del pintor se regodea en la belleza del momento, en la captación de la luz, en el movimiento sensual del agua, y mantiene la mirada utópica de una naturaleza bella y de una manera de vivirla primigenia y que se analiza desde la ensoñación de un naturalismo cargado de significados. Estas imágenes sugieren una visión apacible y sosegada de un entorno palpitante de vida propia, a pesar de su proximidad al bullicio y progreso de la capital. Fillol nos traslada a un lugar sin tiempo, que mantenía un tipo de vida elemental y un tanto primitiva en sus costumbres y en su relación con el hábitat. Una visión sintética de la naturaleza, en la que Fillol muestra su gusto y preferencia por paisajes en los que desplegar el 
estudio de los efectos de luz y color sobre la quietud acuática, con sus tenues ondulaciones, a través de una suave y armónica paleta llena de lirismo. La Sequiota, la acequia que rodea al nordeste la isla del Palmar y la Albufera, es pintada al atardecer, pero se aleja de la mirada inquieta, agitada, de Constantino Gómez. Fillol nos traslada a un mundo de silencio, de quietud, de soledad, características de las que participan otros de sus lienzos como Amanecer en la Albufera, Canal de la Albufera, Barca Albufera, La pesca en el Perelló, Transportando el arroz, Barraca en la Albufera.

La dureza de la vida de estas gentes, que Fillol nunca oculta, no impide transmitir el deslumbramiento estético que le produce el lugar. Pocos artistas valencianos han recreado con tanta emoción y elegancia la serenidad de este espacio acuático; las sensaciones de los reflejos del agua; la armonía y transparencia del paisaje que a veces se hace vaporoso, brumoso y etéreo. Unos paisajes a los que la acción del hombre no ha privado de su singularidad y poesía, sino que ha contribuido a dotarlos de mayor vida a través de una actividad adaptada al lugar y opuesta al paisaje industrial (Alcaide y Pérez Rojas, 2015: 104).

Antonio Fillol y Granell es uno de los artistas valencianos más particulares y atípicos de su generación. Aunque a lo largo de su vida cultivó distintos géneros artísticos, nos cautiva a través de su pintura social y de género; sus obras cobran voz propia en el contexto de la pintura social de su tiempo, creaciones polémicas y controvertidas que nos desvelan un artista pleno de conciencia social y sentido crítico. Sus trabajos no muestran tipos y paisajes llenos de evocaciones regionalistas y costumbristas amables y estereotipadas; se convierten en arma de combate ideológico y de reflexión social dentro de los márgenes del naturalismo imperante. Obras cumbre como La defensa de la choza (1895, Museo del Prado), La bestia humana (1897, Museo del Prado), Los amigos de Jesús (1900, Museo del Prado), o Después de la refriega (1904, Museo de Bellas Artes de Valencia), hablan por sí mismas (Alcaide y Pérez Rojas, 2015; Díez, Barón, 2007). Se ha señalado a menudo que Fillol es el pintor por excelencia de la Albufera. Nadie había descrito con tanta profundidad la vida cotidiana, el mundo del trabajo y de las gentes de la Albufera, con una personalidad diferente, alejada de la contemplación y presente en el mensaje reivindicativo. La significación del poblado de El Palmar, con sus barracas populares y su singularidad, había llamado la atención de Blasco Ibáñez, en su memorable Cañas y Barro, en la que ofrece una descripción alejada del regionalismo costumbrista:

Marañas de hierbas obscuras y gelatinosas como viscosos tentáculos subían hasta la superficie, enredándose con la percha del barquero, y la vista sondeaba inútilmente la vegetación sombría e infecta, en cuyo seno pululaban las bestias del barro. Todos los ojos expresaban el mismo pensamiento: el que cayera allí, difícilmente saldría. (Blasco Ibáñez, Cañas y Barro, 1902)

Fillol es el primero de los pintores valencianos en adentrarse en la captación de la vida y del paisaje de la Albufera. Aunque algunas de sus obras reflejan el interés, modernista o simbolista de fin de siglo, por los paisajes acuáticos. Pero es la narración ligada al trabajo de la tierra, a la familia, a la pesca, a la lucha diaria lo que le preocupa bajo el marco de la belleza, que la horizontalidad del agua y la verticalidad de las cañas y los arrozales le proporcionan (Gracia, 1986: 167-179; León, 1998). 
En ese sentido una de sus obras cumbres es el cuadro La siega del Arroz en la Albufera (1899), que junto a La Bestia Humana presenta en la Exposición Universal de París de 1900. La imagen escenifica dos realidades contrapuestas y enfrentadas: la de los labradores, que iban desecando el lago para ganar zona de cultivo, y la de los pescadores que dependían de él como medio de vida. Vemos a los campesinos, que en grupos apilan las garbas en la barca. Sólo protegidos por sombreros de paja y las fajas para resguardar los riñones del esfuerzo, bajo la potente luz del sol de mediodía, en un día de septiembre calmo y sin brisa. Una estrecha franja de tierra separa el arrozal del lago con las barcas de los pescadores. Al otro lado de la línea divisoria, las velas latinas ondean empujadas por un suave viento, como si nos adentrásemos en otro mundo. La Albufera le inspira una serie de composiciones de diferentes formatos, entre 1899 y 1903. Entre ellas destaca la Familia de pescadores en la playa del Perelló (1902), una aldea de pescadores próxima a la Albufera, en la que incide en un retrato de la familia trabajadora, con cierto énfasis sentimental. La idea de familia idílica, unida por el trabajo, será una de las constantes de su obra dentro de la pintura social, no entendida como denuncia sino para exaltar la unión familiar con el único fin de subsistir (Reyero, 2003). De ese mismo año es La recogida del arroz, una composición en la que se aprecia una tensión palpable entre la belleza del paisaje y el rigor del trabajo (fig.5). La pintura se desenvuelve en una diagonal, que acentúa el esforzado deslizamiento de las barcas arrastradas por los labradores a través de la orilla del canal. Los rostros, hundidos por el esfuerzo, apenas son visibles, como en Courbet o en Millet no tienen protagonismo para enfatizar, así, la carga de los semblantes inclinados. Los lienzos de Fillol narran distintas fases del proceso agrícola, como en Garvejant de 1903, en el que la mirada calma del artista se posa sobre un bancal inundado. La parsimoniosa lentitud se acompasa entre el sosiego de las aguas y el pesado movimiento del buey y del labrador, en su rutinario esfuerzo, diario y repetido.

Pocos artistas han comunicado con tal calidad, a través de la pintura, una visión antropológica de la realidad, una observación tan interiorizada y profunda del mundo que le rodea, analizado y construido bajo la mirada, ideológica, del pintor. ¿Pero, cómo interpretar la simultaneidad de tantas capas de imaginario visual, el simbolismo folclórico y el dramatismo monumental, las cajas de cerillas turísticas y las imágenes con valor de manifiestos sociales? Si dejamos de lado las representaciones posteriores de la Albufera, una buena cantidad de lienzos, que oscilan entre el realismo conservador y la experimentación con la abstracción, podemos buscar las respuestas en otra de las obras clave sobre el territorio. L'Albufera de València de Joan Fuster, acabado en 1970, rinde cuenta de un momento de fractura entre la imagen real y el constructo cultural, punto álgido que coincide con el desplazamiento de significados y la reconstrucción del discurso, que el paisaje de la zona estaba a punto de materializar:

Demà vindràn les urbanizacions venals, especuladores y bancàries, i ja veurem com acaba la història: com o en què (Fuster, 1970).

El cómo merece un punto y aparte, incluso la cronología del qué reta a la linealidad. En 1962 la empresa TEVASA (Terrenos de Valencia S.A.) solicitó y recibió la autorización municipal para elaborar un plan de urbanización de la Dehesa, dos años antes de que Francisco Franco firmase la ley que derogara la legislación que lo prohibía (A.E.O.R.M.A., 1975: 
24-5). Nada más ser conocido el Plan de Ordenación de TEVASA aparecieron las primeras voces aisladas de protesta: de la Real Sociedad Española de Historia Natural, de la Facultad de Ciencias de la Universidad de Valencia, de Félix Rodríguez de la Fuente que abrió el debate en su programa Fauna Salvaje en 1970. Los medios de prensa locales, marginales, como Triunfo, o mayoritarios como Levante y Las Provincias, empezaron, al principio tímidamente, a opinar sobre el incipiente conflicto. A partir de 1970, el tema era omnipresente: mientras el joven profesorado de la Universitat de València y de la Escuela de Arquitectura encauzaba sus denuncias individuales dentro de la filial valenciana de A.E.O.R.M.A, el primer grupo ecologista o los militantes de la Germania Socialista se embarcaban en actos como el sabotaje al campo de golf del Saler (Amer, 2008: 2). Las cartas de lectores a los periódicos comportaban un acto no menos subversivo, firmar con nombres y apellidos declaraciones cuyo verdadero sentido estremece: "Es para mí una inmensa alegría el poder opinar sobre el Saler, ya que hasta ahora se ha silenciado todo en la prensa local" (A.E.O.R.M.A, 1975: 434). El proceso de movilización y consenso tenía multitud de aspectos, algunos de los cuales merecerían un artículo aparte. Es el caso de la decisiva acción de María Consuelo Reyna, un contradictorio personaje procedente de la derecha económica regionalista, germen del "poder valenciano", que en 1973 encabezó la batalla desde las páginas de Las Provincias, orquestando la oposición ciudadana de un modo que se ha considerado paradigmático. La implicación de medios periodísticos nacionales, la reacción de los círculos profesionales y académicos y la inaudita, hasta entonces, presencia de la voz ciudadana en el espacio público (se llegaron a presentar casi 16.000 firmas en contra de la urbanización), pueden ser resumidas con el balance de 1974 que produjo este titular de las Provincias: "12 kilos de documentos, 35 impugnaciones y unos 5000 escritos" (A.E.O.R.M.A, 1975: 64). Hay matices importantes en aquellas voces que apoyaban la posición del Ayuntamiento durante las diferentes fases de reelaboración de los planes de urbanización. Los ciudadanos que la defendían, esgrimían la fe en el progreso, el turismo y en la inversión pública dinamizadora, en breve, prefiguraban un discurso que futuros gobiernos de derechas utilizarán para imponer los nuevos emblemas del valencianismo "modernizado", del tipo de Ciudad de Artes y Ciencias (Prytech, 2010). Fijémonos en cómo nos suenan a conocidas, las notas de estas tempranas opiniones:

Valencia bien merece obra tan extraordinaria que [...] contribuirá aún más a convertirla, con esa bella urbanización, en la ciudad cosmopolita que debe ser y más de conformidad con el papel destacadísimo que en un futuro próximo está llamada a desempeñar en nuestra patria (Carta de lector de Las Provincias, de 1973, en Mateu y Domínguez, 2011: 183).

El análisis de las voces defensoras ofrece un abanico de argumentos de gran novedad conceptual: desde el derecho de la ciudadanía a decidir el destino de un bien público, pidiendo cuentas a los políticos por su destrucción, hasta la responsabilidad de la conservación de los recursos naturales para las generaciones venideras: "El día de mañana, su hijo (...) le va a preguntar: ¿A cómo vendiste el kilo de pino, papá?” (Josep Vicent Marqués, "Tres miradas al Saler. ¿A cómo vendiste el kilo de pino, papá?”. Las Provincias, 18-VI-1974, en A.E.O.R.M.A., 1975). Sin embargo, sería un error no matizar aquella construcción de una 
red conceptual que vinculó patrimonio público, paisaje cultural y acción civil con el espacio Albufera-Saler. En primer lugar, porque el escándalo político pudo conllevar la paralización real de las obras tan solo cuando confluyó con el contexto de una crisis económica que dejaba al descubierto la inviabilidad de los cálculos de los especuladores (A.E.O.R.MA., 1975). En segundo lugar, porque la campaña orquestada por María Consuelo Reyna desde Las Provincias se apropió y redirigió el valor identitario y consensual del símbolo territorial, incluso dando cabida a voces de la izquierda, para enfrentarse al centralismo, para crear el espacio político del valencianismo de derechas, desde el que más tarde se promoverían "antiemblemas", como la Ciudad de las Artes y las Ciencias (Pryterch, 2010). Si salvamos estos importantísimos paréntesis, comprenderemos que el auténtico desplazamiento del simbolismo del espacio Albufera-Saler no terminó, sino más bien empezó, con la protección oficial del territorio. La declaración del parque natural de la Albufera, el 23 de julio de 1986 por la Generalitat Valenciana, es el inicio de un intento de protección que no podía dar solución definitiva a todos los problemas generados durante décadas. Algunos hálitos fracasados como el derogado Plan Especial del Parque natural (1990), son muestra de los titubeos jurídicos frente a una realidad socio-espacial cuya complejidad los supera. Mientras tanto las acciones normativas se multiplicaban: el Decreto 96/1995, de 16 de mayo, aprobaba el Plan de Ordenación de los Recursos Naturales de la Cuenca Hidrográfica de La Albufera...

Así, enlazando con el contenido de los proyectos arquitectónicos, podríamos resumir empezando con una metáfora de la arquitectura del paisaje. En los años noventa, un equipo dirigido por Fernández de la Reguera se encarga de culminar el trabajo de salvación del espacio, comenzado por la campaña popular Saler per al poble y continuado por la paralización de las obras de construcción y creación del Parque Natural de la Albufera. El trabajo del equipo presenta paradojas que superan lo estilístico: pese a la remodelación completa de la infraestructura en caminos sostenibles, el paisaje antiguo era irrecuperable. La destrucción de los ecosistemas de la restinga había borrado, de forma irreversible, las referencias visuales que relacionaban el paisaje de la Dehesa con su pasado. Los especialistas tuvieron que rehacer, re-construir y re-inventar un paisaje, diseñando un nuevo sistema de dunas, malladas y bosque bajo el signo de la geometría (Fernández, 2001: 76-81). El paralelismo resulta tentador. La imagen pública del territorio Albufera-Saler también se reconstruyó, reagrupando restos de elementos antiguos en una visón nueva. A lo largo de los siglos este espacio había simbolizado las utopías de la razón planificadora, la desastrosa acción de un prolongado conflicto socio-económico y, por fin la re-significación de un emblema identitario que unía lo cívico y lo ecológico. Hoy, al margen de las persistentes representaciones a través de nuevas formas plásticas o de las estampas trilladas de las postales, la visión pública del espacio del parque natural tiene nuevos contenidos. Ejemplifica los modos de solución de varios conflictos que superan la simple ordenación normativa. Como por ejemplo, el difícil acercamiento de los grupos afectados por la modernización y aquellos que promueven alternativas a ésta (Rodríguez; Cabrejas, 1998: 197-210). Y también los peligros de la museificación de un territorio habitado, proceso que no coincide con la patrimonialización, puesto que no acaba de abrir las vías hacia las alternativas económicas sostenibles. Todo un laboratorio de soluciones y consensos, a disposición de aquellos segmentos de la sociedad civil que no han aceptado la derrota en la lucha por el otro paisaje patrimonial amenazado, aquel de l'Horta valenciana. 


\section{LAARQUITECTURA PROYECTADA}

A pesar de la imagen proyectada, de la mirada bucólica e idealizada, las metamorfosis de la Albufera y de su Dehesa no han cesado en el tiempo. La construcción, limpieza y ordenación de caminos y tránsitos; la adecuación del lugar al disfrute regio y cortesano o las obras fruto del pensamiento ilustrado y, más tarde, del desarrollismo agrícola al compás del proceso de industrialización, fueron dando forma a su paisaje más o menos actual. Pero además, sobre su espacio ha sido habitual la planificación de proyectos arquitectónicos de mayor calado, capaces de cambiar para siempre la fisonomía del lugar e incluso la propia ordenación territorial valenciana y, por ende, nuestra percepción del paisaje singular.

Una de las primeras acciones proyectadas en los primeros años del siglo XX fue la construcción en la Dehesa del Saler de un primer aeropuerto valenciano (Alba, 2000: 413-434; 2009), actuando el lago como superficie para el amerizaje de los hidroaviones. Este proyecto se halla estrechamente vinculado al desarrollo de la aviación en tierras valencianas. La aparición del primer avión en España no tuvo lugar hasta 1909, en la Exposición Regional de Valencia, seis años más tarde del vuelo de Wrigtht en 1903, aunque ya en 1904 el Ministerio de Fomento había creado un centro de ensayos para la aeroestación (Guijarro, 2001: 30-39). El 5 de septiembre de 1909 el ingeniero Gaspar Brunet construyó un aeroplano con motor, con la colaboración financiera del Ayuntamiento de Valencia, que fue pilotado por Juan Olivert en el que se ha venido considerando el primer vuelo de España. El acontecimiento tuvo lugar en el campo de Paterna con la pretensión de que constituyera un festejo más de la clausura de la Exposición Regional. La Exposición de 1909 ya había generado una mejora considerable en el equipamiento urbano. En ese momento se realizaron las obras de los dos nuevos mercados, el de Colón (1913-1916) y el Mercado Central (1914-1928), el edificio de Correos (1915-1922) y la nueva Casa de la Ciudad en 1906. Las infraestructuras de transporte habían sido incentivadas, ya a mediados de siglo, con la construcción de la primera estación de Ferrocarril del Norte (1852), en lo que hoy es la plaza del Ayuntamiento, seguida por la del ferrocarril del Cabañal (1852), el ferrocarril Valencia Játiva-Almansa (1859), el de ValenciaBarcelona en 1868, el de Valencia-Cuenca, con tramo hasta Buñol (1883), la estación de Utiel (1893), la estación de Aragón y ferrocarril a Calatayud (1902), y la más importante de todas: la construcción de la estación del Norte en 1917. Estas iniciativas forman parte del impulso decisivo que, desde mediados del XIX, llevó a transformar la traza urbana y las infraestruscturas, entre las que se encuentra el proyectado aeropuerto en la Dehesa del Saler.

El decreto ley de 1927 venía a dar respuesta a las necesidades suscitadas tras la implantación de las primeras líneas aeropostales en España. La ley de aeropuertos nacionales de 1927 incluía a Valencia como zona prioritaria para la ubicación y construcción de un aeropuerto. En 1929, se crea la Junta del Aeropuerto de Valencia, formada por miembros pertenecientes a diversas instituciones locales, y presidida por el alcalde, el marqués de Sotelo, con la intención de promover y supervisar la construcción de un aeropuerto adecuado. La preocupación de las autoridades locales por mejorar así la infraestructura urbana, forma parte de la dinámica general que, desde principios de siglo, se venía experimentando en la ciudad de Valencia, fomentando las obras públicas. La construcción de nuevos edificios públicos, y las reformas urbanas responden a la necesidad de adecuar el equipamiento ciudadano al intenso crecimiento económico y al aumento de la población del inicio del siglo, los paradig- 
máticos nuevos tiempos. La consigna del progreso económico vinculado a la modernización y expansión de la ciudad se hacía realidad. La mejora de la trama urbana y de las infraestructuras dota a Valencia de los servicios necesarios en toda ciudad burguesa: elementos e infraestructura del transporte, edificios culturales, asistenciales y recreativos, etc. En este marco, en 1928, bajo la alcaldía del marqués de Sotelo, se aprueba un amplio plan de obras municipales. En 1929 los trabajos de alcantarillado abarcan el casco antiguo, se mejora la red de carreteras reales, que se asfaltaron, y se construyeron dos nuevos puentes sobre el Turia, el de Aragón (1927-1933) y el de Nazaret (1927-1931). Dentro de esta dinámica, no debemos olvidar las obras de mejora y urbanización del puerto bajo control del Ministerio de Fomento, con la construcción de una nueva aduana (1927-1930), y la habilitación del puerto para la hidroaviación (Serra, 1996, Peñín, 1978).

La Junta tras diversos estudios decidió ubicar finalmente el futuro aeropuerto valenciano en los terrenos de la Dehesa del Saler, en la lengua de tierra que separa la Albufera del mar. ¿Cuáles fueron los motivos que llevaron a tal decisión? El terreno seleccionado tenía la extensión de un kilómetro cuadrado aproximadamente. Hoy nos puede parecer extraña, incluso inconsciente tal decisión, pero no estaba alejada de proyectos similares de la época. Era frecuente que la instalación de las primeras infraestructuras aeroportuarias se situase en el litoral: tal es el caso del aeropuerto del Prat, en Barcelona, o el aeródromo del Real Club de Castellón en el Marjal de Benicassim. Uno de los factores fundamentales que se tenía en cuenta, a la hora de elegir el terreno idóneo, era la existencia de una geografía uniforme carente de obstáculos para la aviación, así como la proximidad de una superficie amplia de agua para la hidroaviación, condicionante que explica la elección de la Dehesa del Saler y de la Albufera para la ubicación del futuro aeropuerto valenciano. Su construcción en el litoral venía justificada por la trayectoria de las primeras líneas aeropostales que seguían rutas aéreas en las que, a falta de los precisos instrumentos de hoy en día, se guiaban siguiendo la línea de la costa. La carga simbólica de la Albufera y su Dehesa no pesó en la decisión. La imposición de un progreso voraz se hizo hueco y se inició uno de los primeros conflictos que el desarrollismo había de protagonizar en la modificación del territorio y en su manera de ser percibido.

El proyecto fue encargado a uno de los mejores arquitectos valencianos, Francisco Mora Berenguer (Serra, 1996). Los primeros trabajos del Proyecto de los Edificios para el Aeropuerto en la Dehesa del Saler, conservado en el Archivo municipal de Valencia, se iniciaron en 1929 con la explanación y nivelación de los terrenos de la Dehesa del Saler, una intervención que afectó al ecosistema litoral de la Dehesa y su morfología particular. Las obras comenzaron en el verano de 1929, con una subvención de la Dirección General de Navegación y Transportes Aéreos de 100.000 pesetas (R.O. 17 julio 1929. Gaceta de Madrid 199, 18 julio 1929. Presidencia del Consejo de Ministros). Es más que probable que la nivelación del terreno en el área del actual lago artificial supusiera el principio de la destrucción de las dunas y de la deforestación de la pinada. Los trabajos de la urbanización de TEVASA, acometidos casi cuatro décadas más tarde, profundizaron y generalizaron el daño. Las consecuencias no tardaron en aparecer. Los problemas empezaron en el momento de llevar a cabo la construcción de los edificios e infraestructuras necesarios para el funcionamiento del Aeropuerto. Todos ellos, el edificio o estación Terminal, para dar acogida a los pasajeros, el edificio de servicios, almacenes, hangares, un edificio Casa-Habitación para el portero-guarda, un garaje, un edificio donde se proyectaba 
ubicar las oficinas y el restaurante, y otro que acogía el servicio sanitario, almacén y oficinas de la dirección, fueron proyectados en un estilo de cierta estética Art Déco, que vinculaba la modernidad al nuevo sistema de transporte. También se pensó en el estilo ecléctico, afrancesado, con elementos del estilo Segundo Imperio Francés, para otros edificios, en los que Mora sigue la arquitectura introducida en Valencia en la Exposición Regional de 1909 y planteada en la Estación Marítima (1913). El conocimiento que Francisco Mora había adquirido en la construcción de Edificio para la Compañía de tranvías y ferrocarriles de Valencia (1926), debió influir en el diseño de un ambicioso proyecto arquitectónico. La novedad e innovación de este proyecto, respecto a los edificios aeroportuarios desarrollados en su época, consiste en el tratamiento de las zonas de servicios; descentralizados, adecuados para la espera de los pasajeros que dispondrían de un restaurante, de instalaciones sanitarias en previsión de accidentes aéreos, y de un garaje para los automóviles, génesis de los futuros grandes aparcamientos de los aeropuertos, que tan problemáticos son hoy en día. La singularidad del proyecto de Francisco Mora es evidente si comparamos su diseño, de servicios descentralizados en una serie de edificios anexos que conformarían un amplio complejo, con la tipología edificatoria de los aeropuertos posteriores. Mora, anclado en el pasado, no pudo sustraerse a la herencia aprendida, a ese neohistoricismo que bebe en las fuentes de las formas localistas, propias de la región, especialmente patentes en la utilización del ladrillo como base de la construcción, pero también de la ornamentación. No obstante, el arquitecto intenta mostrarse a la altura, introduciendo algunos signos de modernidad. No utiliza materiales modernos, no hay estructuras férreas ni amplios ventanales acristalados, pero tampoco echa mano del ya manido modernismo, tan utilizado en edificios insignes de Valencia, como la Estación de Ferrocarriles, el Mercado Central o el de Colón. Más bien, aunque tímidamente, introduce algunos aspectos del Art Déco, especialmente en aquellos elementos más destacados como la torre de control (fig.6) en la que el arquitecto juega con los distintos volúmenes geométricos, otorgando elegancia y verticalidad al elemento más insigne de todo el conjunto, cercano a las estéticas soluciones del teatro Rialto de Valencia o a la torre de comunicaciones del Edificio de Correos y Telégrafos de Antonio Palacios, en Madrid. Aunque en el resto de las edificaciones no deja de mostrarse ciertamente tradicional.

El proyecto de Mora jamás se llevó a término, dada la dificultad encontrada en la explanación de los terrenos. Parece que dichos inconvenientes estuvieron relacionados con la falta de firmeza del terreno y la gran cantidad de agua del subsuelo. Desconocemos el impacto exacto que las obras, en parte ejecutadas, tuvieron en su momento, pero podemos prever el resultado de su hipotética realización. El fin de la Dehesa. No esta amenaza, sino tan solo los problemas de edificabilidad, junto al ofrecimiento del alcalde de la ciudad de Manises, hizo que el consistorio valenciano terminase por convencer a la Junta Central de Aeropuertos sobre la conveniencia de modificar los planes iniciales y trasladar la construcción del futuro aeropuerto de Valencia a los terrenos municipales de Manises, allí donde años antes se había instalado el Real Aeroclub de Valencia y su escuela de pilotos. Entre los factores que determinaron tal decisión se halla el hecho de que en tal lugar ya existía una pista de aterrizaje, algunos almacenes y barracones para el repuesto de carburante, por lo que se contaba con una serie de infraestructuras que adelantaban el ingente trabajo que aún quedaba por hacer. Así, por orden de 30 de diciembre de 1932 se organiza en los terrenos cedidos por el Ayuntamiento de Manises un campo de aterrizaje, el primer aeródromo del aeropuerto provisional. 
Figura 6

FRANCISCO MORA, 1929, AEROPUERTO DE VALENCIA EN LA DEHESA DEL SALER. TORRE DE CONTROL, AMMV.

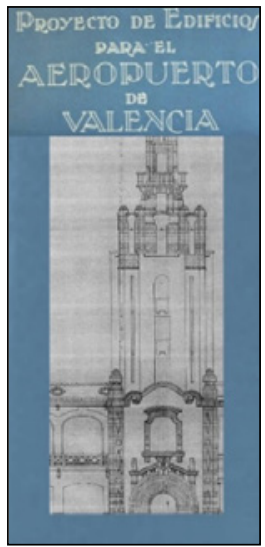

Figura 7

LA URBANIZACIÓN EN LA DEHESA DEL SALER, EN 2015. FOTOGRAFÍA: A. LAFUENTE CARRIÓN.

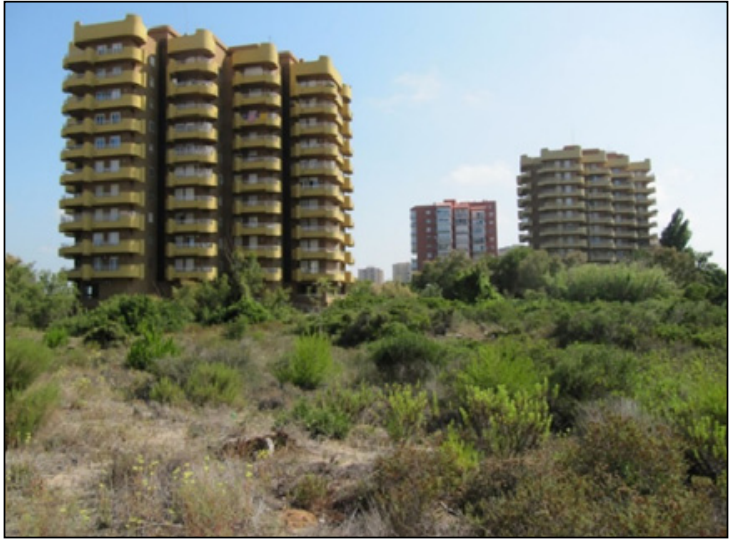

El segundo gran proyecto representativo que se planificó en el espacio de la Dehesa coincidió en el tiempo con el escándalo de la urbanización de TEVASA, pero su posterior realización trascurrió en un ámbito y condiciones muy diferentes. La cesión por parte del Ayuntamiento de $243.700 \mathrm{~m}^{2}$, al Ministerio del Trabajo para la edificación de una nueva Universidad Laboral era de 1967. La elección del arquitecto, que iba a dar vida al conjunto, coincidió con una fase significativa en las relaciones entre el poder totalitario y las formas arquitectónicas que materializaban sus intenciones. Las primeras Universidades Laborales eran imponentes conjuntos neoherrerianos, en el espíritu autárquico populista, unas construcciones poco menos que faraónicas perfectamente adecuadas al espíritu fascista: "Vamos a crear gigantescas Universidades Laborales, castillos de la reconquista nueva", declaraba el ministro J. A. Girón de Velasco en 1950 (Lafuente, Privilegio de introducción, en Vasileva, 
2015: 80-84). El nuevo proyecto, coetáneo a las tendencias desarrollistas, promovidas por los tecnócratas del Opus y su deseo de manifestar apertura y reconciliación con la modernidad occidental, fue encargado a Fernando Moreno Barberá. Se trata de uno de los introductores del racionalismo de las líneas de Corbusier, Mies van der Rohe, o los hitos de la arquitectura moderna latinoamericana. No sabemos si Moreno Barberá pudo presentir el escándalo político en que se envolvería su obra, construyéndola en el Saler. Sí tenemos pruebas de que fue consciente del desastre económico que implicaría. (Moreno Barberá; Memoria del proyecto, en Jordá, 2005: 37). Los costes de urbanización del terreno no eran la única queja del arquitecto respecto a la ubicación: le parecía inconveniente el clima, la necesidad de desecación del suelo, las medidas que le imponía el tamaño reducido para un conjunto de vida y trabajo de más de 5.000 jóvenes. El Saler, con su propio carácter, fisonomía y condiciones particulares, no encajaba en las necesidades de libertad transformadora del racionalismo maduro. La funcionalidad, vista por Moreno Barberá, tenía que subordinar las características físicas de materiales y suelo a un orden destinado a provocar en el ser humano unas reacciones, socialmente productivas, positivas y por supuesto previsibles, debía "Prever e incluso provocar las reacciones que, según su psicología, van a tener los habitantes de cada edificio o conjunto" (Moreno Barberá, 1969, La arquitectura de la Universidad Laboral de Cheste, en Jordá, 2005, Blat Pizarro, 2004). Dentro de esta concepción, el hombre, habitante de la arquitectura creaba alrededor de su actividad e individualidad organizadas un módulo, un espacio óptimo necesario, que la obra construida ordenaba haciéndolo viable. Los elementos visuales tenían que desempeñar y mostrar la funcionalidad, el orden armónico de la máquina para habitar y hacer vida social: contribuir a la mejor distribución de la luz y la sombra, posibilitar la ventilación y la circulación humana, optimizar el esfuerzo vital. ¿Qué lugar podía tener el paisaje preexistente en un esquema tan perfecto?

La comparación del proyecto inicial en el Saler y el finalmente realizado en las cercanías de Cheste, sobre una superficie siete veces más amplia, nos ayuda a acercarnos a la ambigua respuesta. El hecho constructivo real no cambió sustancialmente: tan solo desplegó la idea original. La existencia de un espacio, ahora virgen de condiciones propias y connotaciones particulares, permitió volcar el ideal racionalista. Para el proyecto de Cheste, Moreno Barberá quería lo mismo que hubiera deseado en la primera ubicación: el paisaje "debe penetrar en todos los edificios y lugares donde se desarrolla la vida del alumno, y debe recordarle que es parte integrante de la Naturaleza" (Jordá, 2005: 31). Sin embargo, esta reconciliación entre naturaleza autóctona e ideal funcional pudo florecer tan solo en el lugar de la creación ex nihilo. Un cerro yermo fue excavado, remodelado, rehecho con gran rapidez, movilizando inusitados recursos. La superficie pavimentada llegaría para cubrir 31 estadios de futbol, recuerdan los estudios dedicados al mega-proyecto. $\mathrm{O}$, aun mejor: en el imaginario de los antiguos alumnos perduran otras declaraciones anecdóticas con las que fueron concienciados: el cableado usado para "civilizar" aquella mancha en blanco de espacio natural sería suficiente para llegar varias veces a la luna. El hecho de que luego se produjo una repoblación con especies vegetales autóctonas palidece comparado con el simbolismo de estas consignas. La naturaleza debe ser conocida y respetada solo para que permita crear otra naturaleza mejor. El imaginario del paisaje físico es materia prima necesaria para producir otro imaginario, más manejable e infinitamente más eficiente en sus propósitos. No es de extrañar que la materialización práctica de uno de los más emblemáticos conjuntos de la arquitectura 
racional española literalmente no tuvo cabida en el espacio real e imaginado de la Dehesa, sino tan solo sobre el papel de los planes globalizadores de aquellos círculos del poder, que quedaban completamente ajenos a cualquier realidad física y cultural local. Volvamos al entorno del proyecto que sí se realizó.

El repetitivo sueño de comunicarse por medio de la ampliación de los canales ya indica el grado de inaccesibilidad por tierra de los humedales. El mapa de Cavanilles de 1759 muestra un camino litoral (El Camino Real de Valencia al Perelló), de dudosa viabilidad. Blasco Ibáñez fue el primer artífice del uso público del Saler; su visión de la noble belleza de la pinada de la restinga, "semejante a la de las naves de una catedral inmensa" se transformó fácilmente en el programa político blasquista: las reivindicaciones de la gestión del marjal a fin de paralizar la expansión arrocera acompañaban una campaña de aprovechamiento de la Dehesa para el ocio popular (Sanchis, 2007: 249). El contacto con una naturaleza, mantenida en su estado virgen, tenía que reforzar la salud y ennoblecer el gusto de las clases obreras valencianas que pasarían sus domingos en la restinga litoral y el poder municipal tendría que garantizar el acceso, construyendo una buena carretera. La Universitat de València, apoyó la iniciativa de uso público del Saler y la Albufera, no sin reivindicar, en relación con su demostrado interés científico, la cesión de la gestión del lago a la Universidad para su dedicación al uso científico.

En realidad esta carretera fue construida en tiempos de Primo de Rivera, y cronológicamente es muy cercana al proyecto para el aeropuerto. En definitiva, a lo largo del XX la zona sufrió la realización de dos grandes proyectos infraestructurales: la carretera Nazaret-Oliva, construida en los años veinte, sobre el antiguo camino poco transitable, que recorre el litoral separando los indivisibles ecosistemas de la Dehesa y del lago causando impactos incalculables, y la autopista de Saler, obra llevada a cabo después del inicio del proyecto TEVASA y directamente relacionada con este, que potencia unos desplazamientos en masa hacia la restinga. Unidos a las otras formas de expansión, entre las que ya citamos la ampliación del puerto y la proyección industrial y urbana de la ciudad en la inmediata cercanía, ambas se convirtieron en ejes de la colonización de la metrópoli, que aquí recibió el ambiguo nombre de urbanización.

Durante la polémica sobre los sucesivos planes que sufre la Dehesa del Saler, el poder municipal repetía reiteradamente que su principal propósito era armonizar el uso público y social del espacio de recreo, la atracción del turismo internacional de lujo, en beneficio de la economía común y el respeto hacia la naturaleza. En este último punto se insistía en que la catástrofe ecológica, provocada por la destrucción total del frágil ecosistema de la restinga no tuvo relación con las obras y, además, hasta resultaba remediable por estas propias acciones de civilización del paisaje. El punto del uso cívico fue uno de los más débiles: de los 11 $\mathrm{km}$. de franja litoral urbanizable, tan solo $2,5 \mathrm{~km}$. estaban dedicados a "zona popular" de deporte y ocio, rigurosamente incomunicada con la restante zona de lujo. Y el espacio común debía proporcionar el recreo dominical de 1.000.000 de valencianos, en grupos de 100.000, dotando a cada persona de 2,5 centímetros de playa, como no tardaron en calcular Triunfo y Las Provincias. Un breve recuento de lo planificado, tal como lo reflejaron los informes y la prensa, da claros indicios sobre el contenido simbólico del proyecto:

32 hoteles y moteles de lujo y primera categoría; 162 hoteles y alojamientos de otras categorías; 2.250 apartamentos de torres; 700 apartamientos de bloques altos; 
5.900 viviendas en núcleos coseros; 207 viviendas unifamiliares en el pinar; cuatro iglesias y capillas; palacio de congresos, exposiciones y conciertos; club internacional de presa y residencia para periodistas; palacete de huéspedes ilustres; teatro griego al aire libre; cinco salas de cine; plaza de tientas y venta taurina (...); tres clubs náuticos; faro restaurante; supermercados; galerías comerciales; oficinas; Bancos; agencias de turismo; servicios de correos y teléfonos; tres clínicas de urgencias; estaciones de servicio; grandes talleres de reparaciones de vehículos; dos grupos escolares, 148 viviendas de empleados, club y campo de golf (...); club de tiro de pichón; dos clubs hípicos y otros dos de tenis; así como un parque deportivo con instalaciones para la práctica del futbol, baloncesto, balonmano, atletismo, patinaje, frontones, boleras, piscinas y parque infantil. La urbanización de la Dehesa puede ser resumida en las siguientes cifras (...): superficie total a urbanizar, 871 hectáreas; superficie aproximada de edificación, 150 hectáreas; superficies de zonas deportivas (...) 111 hectáreas (...); red viaria, 30 kilómetros, calles, 20 kilómetros; capacidad total de aparcamientos, 10.000 vehículos; población prevista para la zona residencial, 40.000 personas, y población prevista para la zona popular, 100.000 personas. (Triunfo, 26-9-70. En A.E.O.R.M.A., 1975: 33).

No olvidemos apuntar que, con estos datos, el Ayuntamiento, insistía en que el proyecto afectaría tan solo un 7\% de la pinada. Algo que no deja de tener relación con el cómo se vendía aquel fantasmagórico Qué. Se trataba, según el alcalde, de una "gran realización turística valenciana, la más importante y racional que en el mundo se ha concebido", del "más espectacular escaparate valenciano [que] refleje lo mejor de nuestra personalidad, la más exacta pureza de nuestro estilo"; según los promotores, de "una nueva palabra para el idioma de la construcción" por su revolucionario diseño que combinaba la rentabilidad, la modernidad y la salud (cit. en A.E.O.R.M.A.,1975: 57); para los deseosos, pero incapaces económicamente de disfrutarla, es una visión futurista que haría de "nuestra Valencia" la primera entre las demás ciudades y a la que podían oponerse solo "la mezquindad y la chabacanería" (cit. en A.E.O.R.M.A.,1975: 17). Las palabras clave para la interpretación aparecen diseminadas en los propios planes: personalidad y carácter mediterráneo de todo el conjunto, toques festivocoloristas para la parte popular, fuerte presencia de la edificación en alturas, flexibilidad, modularidad, mejoras radicales del paisaje, como aquel lago artificial para embarcaciones deportivas. Los sucesivos planos hacen transparente esta mezcla de jergas y revelan cómo una planificación completamente ajena a las particularidades del entorno buscó adaptarse a los contratiempos del escándalo económico desembocando en un impotente caos: de la estricta linealidad y modularidad autosuficiente se pasó a las soluciones típicas de aquella "improvisación de intermediarios" denunciada por los analistas de la época, que mimetizaba restos de fórmulas modernas mal digeridas acabando en "la arquitectura de lo provisional" (Fernández Alba, 1972: 74-83).

Los detalles arquitectónicos de lo que hoy en día podemos observar de la urbanización confirman estas definiciones (fig.7). Las altas torres desvirtúan la pretendida estampa funcionalista que algún consejero de TEVASA quiso vender sin haberla entendido. Las vulgares curvas decorativas que aluden a las olas del mar, la ausencia de soluciones destinadas 
a adaptar las segundas viviendas a la abundancia de sol y viento marino, la preocupación de esconder los materiales poco adecuados debajo de acabados con colores de pastelería, todo indica que los constructores se habían alejado equidistantemente tanto del racionalismo moderno como de las soluciones vernáculas, cayendo en un ecléctico estilo internacional de usar y tirar. No nos sorprende de un equipo técnico que fue capaz de edificar, arrasando las dunas, un paseo marítimo de varios metros de altura, que invisibilizaba el mar y completarlo con fantasiosos muretes, para que todo quedase semisepultado por la arena que amontonaba la playa destrozada.

Las actuaciones de reconstrucción del territorio reorganizaron a fondo el sistema de infraestructuras, en busca de soluciones tanto desesperadas como creativas, pero los derribos apenas afectaron a la parte residencial ya construida, dejando a los propietarios el lujo de todo un parque protegido solo para ellos y a nosotros, restos del rompecabezas de aquella estampa publicitaria codiciada y denostada. Pese a su verdadero carácter, precario estructuralmente y kitch si hablamos de formas y estilos, no hay duda de que para el segmento promotor venía a representar un intento de imponer un nuevo emblema identitario que borrase aquellas capas del imaginario que había absorbido el paisaje durante siglos. Intento traicionado por la avidez y la mediocridad de sus ejecutores, pero que dentro del marco concreto y extrapolándolo a un entorno más amplio, no sería ni el primero ni el último.

\section{CONCLUSIONES}

Durante el siglo XX un enclave del territorio valenciano que generaba un creciente número de imágenes e ideas opuestas, se convirtió en objeto de reiterados y frustrados empeños urbanísticos de desproporcionada amplitud. Estos proyectos no fueron más que el final de una larga historia, que encierra las relaciones del espacio Albufera-Saler con la ciudad de Valencia y con su Huerta. A primera vista cada uno de ellos se inscribe en el conocido dilema del mapa y del territorio: intentos procedentes de una voluntad política centralista, alejada de la realidad del suelo al que pretende hacer caber en la camisa de fuerza de la planificación geométrica, arrogante por abstracta. Mientras, en la fractura florecen todo tipo de hierbas salvajes, desde la anécdota cotidiana al abuso criminal. Pero la revisión de las miradas proyectadas sobre esta compleja realidad geográfica, de los siglos de representaciones literarias y plásticas, nos evidencia un conflicto latente mucho más antiguo. La mistificada imagen del artificial paraíso cinegético apenas esconde la visión de caótico refugio para hambrientos cazadores furtivos. La cartografía ilustrada, nacida de la denuncia de tan epatante sinrazón se alterna con las exóticas estampas de los viajeros extranjeros. El poderoso flujo de imágenes del entresiglos, literarias y plásticas, parece vacilar entre descifrar la conflictiva polifonía del espacio social y etiquetarlo en términos de tópicos inamovibles. Nada de esto es comparable con la explosión de significados protagonizada por el siglo XX, tan violentamente ligados a las realidades humanas, que transcienden para siempre de los marcos de los cuadros, para expresarse en manifestaciones, cartas, informes contestatarios y, otra vez, planos que luchan contra otros planos. Las últimas de estas específicas formas de expresión cuentan el difícil equilibrio del Parque Natural de la Albufera, mientras las recientes instalaciones ecologistas y las eternas postales turísticas compiten por los símbolos de las opacas aguas... Es difícil creer que la larga historia mitológico-bélica de Albufera haya terminado. 


\section{BIBLIOGRAFÍA}

A.E.O.R.M.A. (1975): El Saler: dades per a una decisió col·lectiva . Valencia, s.n.

ALBA, E. (2000): "El proyecto del Aeropuerto en la Dehesa del Saler", Saitabi, no 50, 413-434.

ALBA, E. (2009): El Aeropuerto de Manises: de sus inicios a la actualidad, Manises, 2009.

ALBIÑANA, S.; HERNANDEZ, T. (1983): "Notas sobre Técnica y proyectismo en La Albufera y el Júcar en la Edad Moderna”. Estudis. Revista de Historia Moderna, nº10, 55-90.

ALCAIDE, J.L.; PÉREZ ROJAS, F.J. (2015): Antonio Fillol (1870-1930), Naturalismo radical y modernismo, Valencia, Ayuntamiento de Valencia, 2015.

AMER, E. (2008): "Primers anys de l'ecologisme valencià". Disponible en http.//www. accioecologista-agro.org

APPADURAI, A. (2004): "Minorities and the Production of Daily Pace. Interview with Arjun Appadurai", en Feelings are Always Local ( Brouwer J. ; Mulder, A. eds.).Rotterdam, NAI Publishers.

ARCINIEGA, L. (2015): "Catarroja, lugar de paso y esparcimiento: El camino real y el puerto", en Catarroja: Historia, Geografía y Arte, (Hermosilla, J., Alba Pagán, E. coord.). Universitat de València.

ARIAS ANGLÉS, E. (2007): "Nuevos paisajes de Carlos de Haes", Archivo español de arte, Tomo 80, n⿳ $318,177-185$.

BAUMAN, Z. (2000): Liquid Modernity, Cambridge, Polity Press.

BENJAMIN, W. (2005): Libro de los pasajes. Madrid, Akal.

BENJAMIN, W. (2008): Tesis sobre la historia y otros fragmentos. México, Contrahistorias, Green.

BLAT PIZARRO, J. (2004): Fernando. Moreno Barberá: Modernidad y Arquitectura. Barcelona, Fundación Caja de Arquitectos.

BOIRA MAIQUES, J.V. (2004): “El decurs i el discurs de l'extinció de l'horta. Camp i ciutat a València (1865-1966)". Afers. Fulls de Recerca i Pensament, n47, 93-110.

BONET SOLVES, V. (1989): "Paisaje de la realidad en la pintura de valenciana del siglo XIX", Boletín de arte, $\mathrm{n}^{\circ}$ 10, 317-322.

BONET SOLVES, V. (1995): "Los temas de la pintura de paisaje del siglo XIX en Valencia", Saitabi: revista de la Facultat de Geografía i Història, n 45, 1995, 69-78.

CABREJAS, M.; GARCÍA, E. (1997): València, l'Albufera, l'Horta: medi ambient i conflicte social. Valencia, Universitat de València.

COLMEIRO, J. F. (2005): Memoria histórica e identidad cultural. Barcelona, Anthropos.

DÍEZ, J.L.; BARÓN, J. (2007): El siglo XIX en el Prado. Madrid, Museo del Prado.

DÍEZ TORRIJOS, I.; SANCHIS IBOR, C. (2007): “Territorio e imagen. La percepción del paisaje de la Huerta de Valencia”. Saitabi, nº57, 63-76.

FERNÁNDEZ ALBA, A. 81972): La crisis de la arquitectura española: (1939-1972). Madrid, Cuadernos para el Diálogo.

FERNÁNDEZ DE LA REGUERA, A. (2001): “Ordenación del frente litoral de la Albufera sector Dehesa del Saler”. Vía Arquitectura, n¹0, 76-81

FUSTER, J. (1993): L’Albufera de València. Alzira, Bromera (prim. ed. 1970).

GARCIA, E.; CABREJAS, M. (1996): "Medio ambiente y conflicto social: el caso de la Albufera de Valencia". Política y Sociedad, n²3, 75-97. 
GARCIA MONERRIS, E. (1983): "Real Patrimonio y resistencias antifeudales en el País Valenciano (1834-1843)". Estudis d'Historia Contemporània del País Valencià, no 4 , 99-131.

GONZÁLEZ MARTÍ, M. (1952): Cerámica del Levante Español: siglos medievales, (vol. 1), Barcelona, Labor.

GRACIA, C. (1986): "La actividad artística valenciana entre 1880 y 1920", En Vicente Blasco Ibáñez. La aventura del triunfo 1867-1928, Valencia, 167-179.

GREEN, Ch. (2008): "The Memory Effect. Anachronism Time and Motion". Third Text, vol. 22, $\mathrm{n}^{\circ}$ 6, 681-697.

GUASCH, A.M, (2014), "La memoria del otro en la era global”. Revista de Estudios Globales y Arte Contemporáneo, vol. 2, $\mathrm{n}^{\circ} 1,81-91$.

GUIJARRO, L. (2001): "La participación del Ministerio de Fomento en el desarrollo de la aviación se inició en 1904, con la creación del Centro de Ensayos de Aeroestación". Revista del Ministerio de Fomento, № 501, 30-39.

HALBWACHS, M. (1994). Les Cadres sociaux de la mémoire. París, Albin Michel.

HALBWACHS, M. (2004). La memoria colectiva. Zaragoza, Prensa Universitaria de Zaragoza.

HERNÁNDEZ PERELLÓ, M.C. (2015): La influencia de las teorías de la Institución Libre de Enseñanza sobre Estética y Naturaleza en la pintura valenciana de paisaje, Tesis doctoral dirigida por Dra. Ester Alba, Universitat de Valencia.

HUGUET CHANZÀ, J. (1990): Historia de la fotografía valenciana. Valencia: Levante, El Mercantil Valenciano.

JORDÁ SUCH, C. (2005): Universidad Laboral de Cheste, 1967-1969. Almería, Colegio de Arquitectos de Almería.

LEÓN ROCA, J.L. [et al.] (1998): Vicente Blasco Ibáñez: 1898-1998. Centenario de la Barraca, Valencia, Ayuntamiento de Valencia.

LLORENTE, T. (1889): Valencia (vol 2). Barcelona, Estab. Tip. - Ed. de Daniel Cortezo, 1889.

LÓPEZ ALBERT, S. (2008): "Entre valles y monasterios: el paisaje valenciano a finales del siglo XIX”. Ars Longa, Cuadernos de Arte, n¹7, 105-115.

LÓPEZ ALBERT, S. (2006): Una nueva visión de la pintura valenciana: los elementos botánicos y el paisaje. Tesis doctoral inédita. Valencia, Universitat de València.

MATA OLMO, R. (2004): “Agricultura, paisaje y gestión del territorio”. Polígonos: Revista de Geografía, no 14, 97-137.

MATA OLMO, R. (2010): "La dimensión patrimonial del paisaje: Una mirada desde los espacios rurales", en Paisaje y patrimonio (Maderuelo, J., coord.). Madrid: Abada, 31-74.

MATEU, A.; DOMÍNGUEZ, M. (2011): "Inicios del columnismo ambiental en la prensa española: La campaña de Las Provincias sobre la urbanización de El Saler”. Zer, 171-187.

MOMBLANCH Y GONZÁLBEZ, F. de P. (2011): Historia de la Albufera de Valencia. Valencia, Ajuntament de València (prim. ed. 1958).

PEÑÍN, A. (1978): Valencia (1874-1959). Ciudad, Arquitectura y Arquitectos. Valencia, E.T.S. Arquitectura.

PÉREZ ROJAS, F. J. (1998): Tipos y paisajes 1890- 1930. Valencia, Generalitat Valenciana. PRESÈNCIA I CRESPO. A. (1993): Indústria i territori (l'Horta-Albufera). Catarroja: Ajuntament de Catarroja, Servei de Publicacions. 
PRYTERCH, D. L. (2010): "Elegy to an iconographic place: Reconstructing the Regionalism/ Landscap Dialectic in L'Horta de València”. Revista Valenciana d'Etnologia, nº5, 33-53.

RAMOS, R. (1989). «Maurice Halbawchs y la memoria colectiva ». Revista de Occidente, n. ${ }^{\circ} 100,63-81$.

REYERO, C. (2003): Ternura y melodrama. Escenas familiares en tiempos de Sorolla. Valencia, Consorci de Museus de la Generalitat Valenciana.

RIBBANS, G. (1995): Catalunya i Valencia vistes pels viatgers anglesos del segle XVIIIe. Barcelona, Barcino.

RODRÍGUEZ, E. (s.f): "Un poco de historia previa al nacimiento del aeroclub de Valencia". Valencia, Aeroclub de Valencia, inédito.

RODRÍGUEZ VICTORIANO, J.M.; REQUENA I MORA, M. (2012): “Más allá de la medición de la conciencia medioambiental: las investigaciones sobre los discursos medioambientales de la Albufera de Valencia entre 1996 y 2010". Arxius de Ciencies Socials, n ${ }^{\circ}$ 27, p. 165-182.

RODRIGUEZ VICTORIANO, J. M.; CABREJAS HERNANSANZ, M. (1998): “Trabajo y medio ambiente: el problema ecologico-social del parque natural de la Albufera”. Arxius de Sociologia, n², p. 197-210.

ROMERO J.; F. Miquel (eds.) (2012): La Huerta de Valencia: un paisaje cultural con futuro incierto. Valencia, Publicacions de la Universitat de València.

ROSSELLÓ I VERGER, V. M. (1995): L'Albufera de València. Barcelona, Publicacions de l'Abadia de Montserrat.

SALA, D. (1999): Viajeros franceses por la Valencia del siglo XVII. Valencia, Ajuntament de Valencia.

SÁNCHEZ ZAPATERO, J (2010): "La cultura de la memoria". Pliegos de Yuste, no 11-12, 25-30.

SANCHIS IBOR, C. (1998): De la gola a les goles: canvi ambiental secular a l'Albufera de València. Valencia, Fundació Bancaixa.

SANCHIS IBOR, C. (2007): “La construcció d'una icona paisatgística. L'Albufera de Valéncia (1889-1939)". Saitabi, nº57, p. 241-260

SANMARTÍN ARCE, R. (2008): "Cambio social y valores culturales en una pequeña comunidad”. Revista de Dialectología y Tradiciones, 2008, n 63(2), p. 243-259

SANZ CAÑADA E. [et al.] (1991): Plan especial de protección del Parque Natural de la Albufera. València, Conselleria de Medi Ambient.

SERRA, A. (1996): Eclecticismo Tardío y Art Decó en la ciudad de Valencia (1926-1936). Estudis.

SHOTTER, J. (1990). «La construcción social de la memoria y el olvido», en Memoria compartida. La naturaleza social del recuerdo y del olvido (Middleton D.; Edwards, D. comps.). Barcelona, Paidós, 137-156.

SOLER, A. (1998): "Un país de set jornades de llong: Aspectes de la reordenació del territori colonial de Valencia per Jaume I'. Cuadernos de Geografía, nº 63, 217-244.

SORRIBES I MONRABAL, J. (1985): Desarrollo capitalista y proceso de urbanización en el País Valenciano. Valencia: Institución Alfonso el Magnánimo.

VASILEVA IVANOVAA.; ALBA PAGÁN E. [et al.]. (2015): Fernando Moreno Barberá: un arquitecto para la universidad. Valencia: Universitat de València. 